\title{
The International CAPM and a wavelet-based decomposition of Value at Risk
}

\author{
Viviana Fernandez ${ }^{1}$
}

\begin{abstract}
In this article, we formulate a time-scale decomposition of an international version of the CAPM that accounts for both market and exchange-rate risk. In addition, we derive an analytical formula for time-scale value at risk and marginal value at risk (VaR) of a portfolio. We apply our methodology to stock indices of seven emerging economies belonging to Latin America and Asia, the sample period 1990-2004. Our main conclusions are the following. First, the estimation results hinge upon the choice of the world market portfolio. In particular, the stock markets of the sampled countries appear to be more integrated with other emerging countries than with developed ones. Second, value at risk depends on the investor's time horizon. In the short run, potential losses are greater than in the long run. Third, additional exposure to some specific stock indices will increase value at risk to a greater extent, depending on the investment horizon. Our results go in line with recent research in asset pricing that stresses the importance of heterogeneous investors.
\end{abstract}

JEL: C22, G15 Keywords: wavelets, ICAPM, value at risk.

\footnotetext{
${ }^{1}$ Center for Applied Economics (CEA), Department of Industrial Engineering at the University of Chile. Postal: Avenida Republica 701, Santiago-Chile. E-mail: vfernand@dii.uchile.cl. Funds provided by FONDECYT Grant No. 1050486 and by an institutional grant of the Hewlett Foundation to CEA are greatly acknowledged. All remaining errors are the author's.
} 


\section{Introduction}

The capital asset pricing model (CAPM), a corner-stone of modern finance, states that the risk premium of an individual asset equals its beta times the risk premium on the market portfolio. Beta measures the degree of co-movement between the asset's return and the return on the market portfolio. In other words, beta quantifies the systematic risk of an asset—i.e., the amount of risk that cannot be diversified away.

In recent years, however, the CAPM has been questioned by several empirical studies. In particular, Fama and French (1992) announced the death of beta based on the fact that it does a poor job of explaining the cross-section variation of average returns, as opposed to the book-to-market ratio and market capitalization. Kothari and Shanken (1998), however, conclude that Fama and French's results hinge on using monthly rather than yearly returns. Kothari and Shanken argue that the use of annual returns to estimate betas helps to circumvent measurement problems caused by non-synchronous trading, seasonality in returns, and trading frictions.

Simultaneously, several authors have worked on theoretical extensions of the CAPM: the after-tax CAPM, which accounts for the fact that investors have to pay higher taxes on high dividend-yield stocks, and, therefore, they must be compensated with higher pre-tax returns; the inter-temporal CAPM, which deals with a multi-period setting; the consumption CAPM, which states that security returns are highly correlated with aggregate economic output, as investors are concerned with protecting their consumption over economic slowdowns; and, the international asset pricing model, which establishes the conditions under which fully integrated capital markets are in equilibrium (see Megginson, 1997, for a thorough discussion and citations).

Another theme that has been covered by the empirical literature on the CAPM, and which is related to our article, is the testing of asset pricing models that allow for a timevarying beta, a time-varying risk premium, or for both. Typically, researchers have resorted to GARCH and GARCH-in-mean processes for such testing (e.g., Engle, Lilien and Robins, 1987; Bollerslev, Engle, and Wooldridge, 1988). An alternative, but promising, approach is wavelet analysis. This is a refinement of the Fourier analysis that, among many other applications, allows for a time-scale decomposing of financial data (i.e., highfrequency or noisy components and low-frequency or trend components). Such decomposition makes it possible to compute pair-wise correlations at different timehorizons.

Early studies that utilize wavelet methods are Ramsey, Usikov, and Zaslavsky (1995) and Ramsey and Zhang (1996, 1997), which concentrate on stock markets and foreign exchange rate dynamics. More recent contributions have dealt with the permanent income hypothesis, the relation between futures and spot prices, the estimation of systematic risk of an asset (beta), seasonality filtering of time-series data, time and scale dependency of intraday Asian spot exchange rates, and heterogeneous trading in commodity markets, among other themes (e.g., Ramsey and Lampart 1998; Li and Stevenson 2001; Gençay, Whitcher, and Selcuk 2001, 2003, 2005; Whitcher 2004; Karuppiah and Los 2005; Connor and Rossiter 2005). A thorough discussion of the use of 
wavelets in economics and finance can be found in the survey articles by Ramsey (1999, 2002).

This article concentrates on a wavelet-based international asset pricing model (ICAPM). That is, we estimate ICAPM models for different time horizons. A concrete application of our estimation results is the computation of the value at risk for a multicountry portfolio. Previous studies have stressed the importance of exchange rate risk. Indeed, the evidence has shown that there can be considerable departures from the purchasing power parity (PPP), so exchange risk should be priced (e.g., Adler and Dumas 1983). At the same time, several theoretical models have stressed the importance of this risk factor (e.g., Solnik 1974; Adler and Dumas 1983; Stulz 1971, 1992). Empirical support for the existence of a foreign exchange risk premium has been found by Dumas and Solnik (1995) and De Santis and Gerard (1998). Additional evidence in favor of the ICAPM over the CAPM is documented by Dumas (1994).

The contribution of our work is two fold. First, applications of wavelet analysis to financial risk have dealt exclusively with the single-country CAPM (e.g., Gençay, Whitcher, and Selcuk 2003, 2005), where exchange-rate risk is non-existent. Second, our study introduces the concepts of time-scale value at risk and time-scale marginal value at risk. Recent research in the area of asset pricing has started to account for agents' heterogeneous time horizons in financial markets. As Connor and Rossiter (2005) point out for the specific case of commodity markets, long-horizon traders will essentially focus on price fundamentals that drive overall trends, whereas short-term traders will primarily react to incoming information within a short-term horizon. Hence, market dynamics in the aggregate will be the result of the interaction of agents with heterogeneous time horizons. A similar intuition can be applied to our model: market and exchange risk and, hence, potential portfolio losses will depend upon the investor's time horizon. In the aggregate, market and exchange-rate risks will be the outcome of the different time-horizon investors.

This article is organized as follows. Section 2 is divided into three parts. Section 2.1 presents a brief theoretical background on the version of the ICAPM we will use in our empirical analysis. Section 2.2 presents a brief description of the discrete wavelet transforms (DWT) and the maximal overlap DWT (MODWT). Section 2.3 presents our derivation of the time-scale value at risk and the marginal value at risk of a portfolio comprised by an arbitrary number of assets. Section 3 applies our methodology to stock indices of seven emerging economies belonging to Latin America and Asia, for the sample period 1990-2004. Finally, Section 4 presents our main conclusions.

\section{Theoretical issues}

For simplicity, we will postulate that an investment in a country portfolio (measured in local currency) is subject to two sources of risk, namely, the country index's sensitivity to a global portfolio and the performance of the domestic currency relative to the foreign currency. Our viewpoint will be that of an US investor, so we will take the US dollar as the foreign currency. This formulation is certainly parsimonious, but it simplifies enormously the derivation of a formula for the value at risk of a portfolio invested on several country 
indices. Despite the simplicity of our model, we will allow for the existence of correlation among the exchange rates of different countries.

Section 2.1 describes the formulation of our two-country CAPM. Section 2.2 focuses on the statistical technique of wavelets, whereas Section 2.3 obtains an analytic formula for the time-scale value at risk (VaR) of $k$ assets and the time-scale marginal VaR of an individual asset.

2.1 The international CAPM: the two-country case

The expected risk premium of a domestic asset is given by (see Sercu and Uppal 1995, chapter 22)

$$
\mathrm{E}\left(\mathrm{r}_{\mathrm{i}}-\mathrm{r}\right)=\psi_{1} \operatorname{cov}\left(\mathrm{r}_{\mathrm{i}}, \mathrm{r}_{\mathrm{w}}\right)+\psi_{2} \operatorname{cov}\left(\mathrm{r}_{\mathrm{i}}, \mathrm{s}\right)
$$

where $r_{i}$ and $r_{w}$ are the returns on the domestic asset and the world market portfolio, respectively (both expressed in local currency), $\mathrm{s}$ is the percent change in the exchange rate between the domestic and the foreign currency, and $\psi_{1}$ and $\psi_{2}$ represent the prices of the corresponding covariance risks.

In this model, the expected risk premium consists of two risk premiums for covariance risks. The intuition behind the first risk premium is similar to that of the singlecountry CAPM. The premium for exchange risk covariance reflects the fact that investors are also concerned about the covariance of local-currency returns with the exchange rate.

In order to determine $\psi_{1}$ and $\psi_{2}$, two benchmarks are taken, namely, the world market portfolio and the foreign Treasury bond. Therefore, we have the following system of two equations in the two unknowns $\psi_{1}$ and $\psi_{2}$ :

$$
\begin{gathered}
\mathrm{E}\left(\mathrm{r}_{\mathrm{w}}\right)-\mathrm{r}=\psi_{1} \operatorname{cov}\left(\mathrm{r}_{\mathrm{w}}, \mathrm{r}_{\mathrm{w}}\right)+\psi_{2} \operatorname{cov}\left(\mathrm{r}_{\mathrm{w}}, \mathrm{s}\right) \\
=\psi_{1} \operatorname{var}\left(\mathrm{r}_{\mathrm{w}}\right)+\psi_{2} \operatorname{cov}\left(\mathrm{r}_{\mathrm{w}}, \mathrm{s}\right)
\end{gathered}
$$

The expression $\mathrm{E}(\mathrm{s})+\mathrm{r}^{*}$ represents the expected return on the Treasury bond in terms of the local currency. Under the assumption that $\operatorname{cov}\left(r_{\mathrm{w}}, \mathrm{s}\right)=0, \psi_{1}$ and $\psi_{2}$ boil down to

$$
\psi_{1}=\frac{\mathrm{E}\left(\mathrm{r}_{\mathrm{w}}\right)-\mathrm{r}}{\operatorname{var}\left(\mathrm{r}_{\mathrm{w}}\right)} \quad \psi_{2}=\frac{\mathrm{E}(\mathrm{s})+\mathrm{r}^{*}-\mathrm{r}}{\operatorname{var}(\mathrm{s})}
$$

After substituting (3) into (1), we obtain 


$$
\begin{gathered}
E\left(r_{i}-r\right)=\frac{\operatorname{cov}\left(r_{i}, r_{w}\right)}{\operatorname{var}\left(r_{w}\right)} E\left(r_{w}-r\right)+\frac{\operatorname{cov}\left(r_{i}, s\right)}{\operatorname{var}(s)} E\left(s+r^{*}-r\right) \\
\equiv \alpha_{1 i} E\left(r_{w}-r\right)+\alpha_{2 i} E\left(s+r^{*}-r\right)
\end{gathered}
$$

where $\alpha_{1 i}$ is the sensitivity of asset $i$ to the world market portfolio, and $\alpha_{2 i}$ is the asset's relative exchange rate risk.

If the world market portfolio is denominated in the foreign currency instead ${ }^{2}$, equation (1) can be restated as

$$
\mathrm{E}\left(\mathrm{r}_{\mathrm{i}}-\mathrm{r}\right)=\phi_{1} \operatorname{cov}\left(\mathrm{r}_{\mathrm{i}}, \mathrm{r}_{\mathrm{w}}^{*}+\mathrm{s}\right)+\phi_{2} \operatorname{cov}\left(\mathrm{r}_{\mathrm{i}}, \mathrm{s}\right)
$$

Similarly, by taking as benchmarks the world market portfolio and the foreign Treasury bond, we have

$$
\begin{aligned}
& \mathrm{E}\left(\mathrm{r}_{\mathrm{w}}^{*}+\mathrm{s}\right)-\mathrm{r}=\phi_{1} \operatorname{var}\left(\mathrm{r}_{\mathrm{w}}^{*}+\mathrm{s}\right)+\phi_{2}\left(\operatorname{cov}\left(\mathrm{r}_{\mathrm{w}}^{*}, \mathrm{~s}\right)+\operatorname{var}(\mathrm{s})\right) \\
& \mathrm{E}(\mathrm{s})+\mathrm{r}-\mathrm{r}^{\mathrm{r}}=\phi_{1} \operatorname{cov}\left(\mathrm{s}, \mathrm{r}_{\mathrm{w}}^{*}\right)+\left(\phi_{1}+\phi_{2}\right) \operatorname{var}(\mathrm{s})
\end{aligned}
$$

After solving for $\phi_{1}$ and $\phi_{2}$ rearranging terms, we get that ${ }^{3}$

$$
\begin{gathered}
E\left(r_{i}-r\right)=\frac{\operatorname{cov}\left(r_{i}, r_{w}^{*}\right)}{\operatorname{var}\left(r_{w}^{*}\right)} E\left(r_{w}^{*}-r^{*}\right)+\frac{\operatorname{cov}\left(r_{i}, s\right)}{\operatorname{var}(s)} E\left(s+r^{*}-r\right) \\
\equiv \beta_{1 i} E\left(r_{w}^{*}-r^{*}\right)+\beta_{2 i} E\left(s+r^{*}-r\right)
\end{gathered}
$$

In practice, however, the world market portfolio (measured in either local or foreign currency) and the exchange rate variation will not be necessarily orthogonal. Then the sensitivities to the risk factors, $\beta_{1}$ and $\beta_{2}$, have to be jointly estimated from a linear regression model. For instance, let us consider the regression representation of equation (7)

$$
\mathrm{r}_{\mathrm{i}}=\beta_{0 \mathrm{i}}+\beta_{1 \mathrm{i}} \mathrm{r}_{\mathrm{w}}^{*}+\beta_{2 \mathrm{i}} \mathrm{s}+\varepsilon_{\mathrm{i}}
$$

where $\varepsilon_{\mathrm{i}}$ is an error term that satisfies all the assumptions of the linear regression model. Estimates of both beta and gamma can be obtained by ordinary least-squares. From elementary econometrics (see, for instance, Johnston (1984), chapter 3), we have that

\footnotetext{
${ }^{2}$ In the empirical section of the paper, our proxies of the world market portfolio are denominated in US dollars, which we take as the foreign currency.

${ }^{3}$ This calculation assumes that $\operatorname{cov}\left(\mathrm{r}_{\mathrm{w}}^{*}, \mathrm{~s}\right)=0$.
} 


$$
\hat{\beta}_{1 \mathrm{i}}=\frac{\hat{\delta}_{\mathrm{ri}_{\mathrm{i}} \mathrm{w}}-\hat{\delta}_{\mathrm{r}_{\mathrm{i}}} \hat{\delta}_{\mathrm{sr}_{\mathrm{w}}}}{1-\hat{\delta}_{\mathrm{r}_{\mathrm{w}} \mathrm{s}} \delta_{\mathrm{sr}_{\mathrm{w}}}} \quad \hat{\beta}_{2 \mathrm{i}}=\frac{\hat{\delta}_{\mathrm{r}_{\mathrm{i}} \mathrm{s}}-\hat{\delta}_{\mathrm{r}_{\mathrm{i}} \mathrm{r}_{\mathrm{w}}} \hat{\delta}_{\mathrm{r}_{\mathrm{w}} \mathrm{s}}}{1-\hat{\delta}_{\mathrm{r}_{\mathrm{w}} \mathrm{S}} \hat{\delta}_{\mathrm{sr}_{\mathrm{w}}}}
$$

where $\hat{\delta}_{\mathrm{r}_{\mathrm{i}} \mathrm{r}_{\mathrm{w}}}$ is the slope of a regression of $\mathrm{r}_{\mathrm{i}}$ on a constant term and $\mathrm{r}_{\mathrm{w}}$, that is, $\hat{\delta}_{\mathrm{r}_{\mathrm{i}} \mathrm{r}}=\frac{\sum_{\mathrm{t}}\left(\mathrm{r}_{\mathrm{it}}-\overline{\mathrm{r}}_{\mathrm{i}}\right)\left(\mathrm{r}_{\mathrm{wt}}-\overline{\mathrm{r}}_{\mathrm{w}}\right)}{\sum_{\mathrm{t}}\left(\mathrm{r}_{\mathrm{wt}}-\overline{\mathrm{r}}_{\mathrm{w}}\right)^{2}}$, etcetera.

The $\mathrm{R}^{2}$ of the regression model in (8) can be obtained as

$$
\mathrm{R}^{2}=\frac{\rho_{\mathrm{r}_{\mathrm{i}} \mathrm{r}_{\mathrm{w}}}^{2}+\rho_{\mathrm{r}_{\mathrm{i}} \mathrm{s}}^{2}-2 \rho_{\mathrm{ri}_{\mathrm{i}}} \rho_{\mathrm{r}_{\mathrm{i}}} \rho_{\mathrm{r}_{\mathrm{w}} \mathrm{s}}}{1-\rho_{\mathrm{r}_{\mathrm{w}} \mathrm{s}}^{2}}
$$

where $\rho_{\mathrm{r}_{\mathrm{i}} \mathrm{r}_{\mathrm{w}}}$ is the sample correlation coefficient between $\mathrm{r}_{\mathrm{i}}$ and $\mathrm{r}_{\mathrm{w}}$, etcetera.

We will use these equations later as a benchmark for our wavelet-based decomposition.

\subsection{The Discrete Wavelet Transform}

A wavelet or short wave is similar to a sine and cosine function in that it also oscillates about zero (see, for instance, Percival and Walden, 2000; Gençay, Selçuk, and Whitcher, 2002). However, as its name indicates, oscillations of a wavelet fade away about zero, and the function is localized in time or space. ${ }^{4}$ In wavelet analysis, a signal (i.e., a sequence of numerical measurements) is represented as a linear combination of wavelet functions.

In particular, a wavelet allows for decomposing a signal into multi-resolution components: fine and coarse resolution components. There are father and mother wavelets. Father wavelets $(\phi)$ are good at representing the smooth and low-frequency parts of a signal, whereas mother wavelets $(\psi)$ are good at representing the detailed and highfrequency parts of a signal. In particular, the orthogonal wavelet series approximation to a continuous signal $f(t)$ is given by

$$
\mathrm{f}(\mathrm{t}) \approx \sum_{\mathrm{k}} \mathrm{s}_{\mathrm{J}, \mathrm{k}} \phi_{J, \mathrm{k}}(\mathrm{t})+\sum_{\mathrm{k}} \mathrm{d}_{\mathrm{J}, \mathrm{k}} \psi_{\mathrm{J}, \mathrm{k}}(\mathrm{t})+\sum_{\mathrm{k}} \mathrm{d}_{\mathrm{J}-1, \mathrm{k}} \psi_{\mathrm{J}-1, \mathrm{k}}(\mathrm{t})+\ldots+\sum_{\mathrm{k}} \mathrm{d}_{1, \mathrm{k}} \psi_{1, \mathrm{k}}(\mathrm{t})
$$

where $\mathrm{J}$ is the number of multi-resolution components or scales, and $\mathrm{k}$ ranges from 1 to the number of coefficients in the corresponding component. The coefficients $\mathrm{s}_{\mathrm{J}, \mathrm{k}}, \mathrm{d}_{\mathrm{J}, \mathrm{k}}, \ldots, \mathrm{d}_{1, \mathrm{k}}$ are the wavelet transform coefficients, whereas the functions $\phi_{\mathrm{j}, \mathrm{k}}(\mathrm{t})$ and $\psi_{\mathrm{j}, \mathrm{k}}(\mathrm{t})$ are the approximating wavelet functions. These functions are generated from $\phi$ and $\psi$ as follows

\footnotetext{
${ }^{4}$ Mathematically, a function $\varpi($.$) defined over the entire real axis is called a wavelet if \varpi(t) \rightarrow 0$ as $t \rightarrow \pm \infty$.
} 


$$
\phi_{j, k}(t)=2^{-j / 2} \phi\left(\frac{t-2^{j} k}{2^{j}}\right) \quad \psi_{j, k}(t)=2^{-j / 2} \psi\left(\frac{t-2^{j} k}{2^{j}}\right) .
$$

Expression (11) is an orthogonal approximation because the basis functions $\phi_{\mathrm{j}, \mathrm{k}}(\mathrm{t})$ and $\psi_{\mathrm{j}, \mathrm{k}}(\mathrm{t})$ are orthogonal by construction. The wavelet coefficients can be approximated by the following integrals

$$
\mathrm{s}_{\mathrm{J}, \mathrm{k}} \approx \int \phi_{\mathrm{J}, \mathrm{k}}(\mathrm{t}) \mathrm{f}(\mathrm{t}) \mathrm{dt} \quad \mathrm{d}_{\mathrm{j}, \mathrm{k}} \approx \int \psi_{\mathrm{j}, \mathrm{k}}(\mathrm{t}) \mathrm{f}(\mathrm{t}) \mathrm{dt}, \mathrm{j}=1,2, \ldots, \mathrm{J}
$$

These coefficients are a measure of the contribution of the corresponding wavelet function to the total signal. On the other hand, the approximating wavelet functions $\phi_{\mathrm{j}, \mathrm{k}}(\mathrm{t})$ and $\psi_{\mathrm{j}, \mathrm{k}}(\mathrm{t})$ are scaled and translated versions of $\phi$ and $\psi$. As equation (12) indicates, the scale or dilation factor is $2^{j}$, whereas the translation or location parameter is $2^{j} \mathrm{k}$. As $\mathrm{j}$ gets largeri.e., as we move towards the smoother or low frequency components of the data-so does the scale factor $2^{\mathrm{j}}$, and the functions $\phi_{\mathrm{j}, \mathrm{k}}(\mathrm{t})$ and $\psi_{\mathrm{j}, \mathrm{k}}(\mathrm{t})$ get shorter and more spread out.

In general, there is no close-form solution for father and mother wavelets, and they have to be computed by the so-called dilation equations:

$$
\phi(\mathrm{x})=\sqrt{2} \sum_{\mathrm{k}} \mathrm{l}_{\mathrm{k}} \phi(2 \mathrm{x}-\mathrm{k}) \quad \psi(\mathrm{x})=\sqrt{2} \sum_{\mathrm{k}} \mathrm{h}_{\mathrm{k}} \phi(2 \mathrm{x}-\mathrm{k})
$$

The $l_{k}$ and $h_{k}$ coefficients are called the scaling (low-pass) and wavelet (high-pass) filter coefficients, respectively, which are defined by

$$
\mathrm{l}_{\mathrm{k}}=\frac{1}{\sqrt{2}} \int \phi(\mathrm{t}) \phi(2 \mathrm{t}-\mathrm{k}) \mathrm{dt} \quad \mathrm{h}_{\mathrm{k}}=\frac{1}{\sqrt{2}} \int \psi(\mathrm{t}) \phi(2 \mathrm{t}-\mathrm{k}) \mathrm{dt}
$$

and, they are related through $l_{k}=(-1)^{k+1} h_{L-1-k}, k=0, . ., L-1$, where $L$ is the width of the wavelet filter. ${ }^{5}$

Applications of wavelet analysis commonly utilize a discrete wavelet transform (DWT). The DWT calculates the coefficients of the approximation in (1) for a discrete signal of final extent, $f_{1}, f_{2}, . ., f_{n}$. That is, it maps the vector $\mathbf{f}=\left(f_{1}, f_{2}, \ldots, f_{n}\right)^{\prime}$ to a vector of $n$ wavelet coefficients that contains $s_{J, k}$ and $d_{j, k}, j=1,2, \ldots$, J. The $s_{J, k}$ are called the smooth coefficients and the $\mathrm{d}_{\mathrm{j}, \mathrm{k}}$ are called the detail coefficients. Intuitively, the smooth coefficients represent the underlying smooth behavior of the data at the coarse scale $2^{\mathrm{J}}$, whereas the detail coefficients provide the coarse scale deviations from it.

\footnotetext{
${ }^{5}$ In practical applications, we deal with sequences of values (i.e., time series) rather than functions defined over the entire real axis. Therefore, instead of using actual wavelets, we work with short sequences of values named wavelet filters, denoted by $\left\{\mathrm{h}_{\mathrm{k}}\right\}_{\mathrm{k}=0}^{\mathrm{L}}$. The number of values in the sequence is called the width of the wavelet filter, and it is denoted by $\mathrm{L}$.
} 
When the length of the data, $n$, is divisible by $2^{\mathrm{J}}$, there are $n / 2^{\mathrm{j}} \mathrm{d}_{\mathrm{j}, \mathrm{k}}$-coefficients at scale $j=1, . ., J-1$. Similarly, at the coarsest scale, there are $n / 2^{J} d_{J, k^{-}}$coefficients and $n / 2^{J} s_{J, k^{-}}$ coefficients. Altogether, there are $\mathrm{n}$ wavelets coefficients. The number of coefficients at a given scale is related to the width of the wavelet function. For instance, at the finest scale $\mathrm{j}=1$, it takes $\mathrm{n} / 2$ terms — which are contained in the crystal $\mathbf{d}_{1}=\left(\mathrm{d}_{1,1}, \mathrm{~d}_{1,2}, \ldots, \mathrm{d}_{1, \mathrm{n} / 2}\right)^{\prime}$ - for the functions $\psi_{1, \mathrm{k}}(\mathrm{t})$ to cover the interval $1 \leq \mathrm{t} \leq \mathrm{n} .{ }^{6}$

Expression (1) can be rewritten as

$$
\mathrm{f}(\mathrm{t}) \approx \mathrm{S}_{\mathrm{J}}(\mathrm{t})+\mathrm{D}_{\mathrm{J}}(\mathrm{t})+\mathrm{D}_{\mathrm{J}-1}(\mathrm{t})+\ldots+\mathrm{D}_{1}(\mathrm{t})
$$

where $\mathrm{S}_{J}(\mathrm{t})=\sum_{\mathrm{k}} \mathrm{s}_{J, \mathrm{k}} \phi_{J, \mathrm{k}}(\mathrm{t})$ and $\mathrm{D}_{\mathrm{J}}(\mathrm{t})=\sum_{\mathrm{k}} \mathrm{d}_{\mathrm{j}, \mathrm{k}} \psi_{J, \mathrm{k}}(\mathrm{t})$ are denominated the smooth and detail signals, respectively.

The terms in expression (10) represent a decomposition of the signal into orthogonal signal components $\mathrm{S}_{\mathrm{J}}(\mathrm{t}), \mathrm{D}_{\mathrm{J}}(\mathrm{t}), \mathrm{D}_{\mathrm{J}-1}(\mathrm{t}), \ldots, \mathrm{D}_{1}(\mathrm{t})$ at different resolutions. And, hence, the approximation in (16) is called a multi-resolution decomposition (MRD).

\subsubsection{Wavelet variance and covariance: DWT versus MODWT}

Wavelet-variance analysis consists of partitioning the variance of a time series into pieces that are associated to different time scales. It tells us what scales are important contributors to the overall variability of a series (see Percival and Walden, 2000). In particular, let $\mathrm{x}_{1}, \mathrm{x}_{2}, \ldots, \mathrm{x}_{\mathrm{n}}$ be a time series of interest, which is assumed to be a realization of a stationary process with variance $\sigma_{\mathrm{X}}^{2}$. If $\mathrm{v}_{\mathrm{X}}^{2}\left(\tau_{\mathrm{j}}\right)$ denotes the wavelet variance for scale $\tau_{\mathrm{j}} \equiv 2^{\mathrm{j}-1}$, then the following relationship holds:

$$
\sigma_{\mathrm{X}}^{2}=\sum_{\mathrm{j}=1}^{\infty} \mathrm{v}_{\mathrm{x}}^{2}\left(\tau_{\mathrm{j}}\right)
$$

where the square root of the wavelet variance is expressed in the same units as the original data.

Let $n_{j}^{\prime}=\left\lfloor n / 2^{j}\right\rfloor$ be the number of discrete-wavelet transform (DWT) coefficients at level $\mathrm{j}$, where $\mathrm{n}$ is the sample size, and let $\mathrm{L}_{j}^{\prime} \equiv\left\lceil(\mathrm{L}-2)\left(1-\frac{1}{2^{\mathrm{j}}}\right)\right\rceil$ be the number of DWT

\footnotetext{
${ }^{6}$ In practice, the DWT is calculated by using a filter cascade, where the wavelet filter $\left\{\mathrm{h}_{\mathrm{k}}\right\}$ and its associated scaling filter $\left\{l_{k}\right\}$ given by (15), are used in a pyramid algorithm to decompose a time series. To generate the first level of coefficients, the original data is filtered by convolving it separately with the wavelet and scaling filters. Next, every other point from each filter output is thrown out, and the remaining filter outputs are defined as the unit level $(j=1)$ wavelet and scaling coefficients. For $\mathrm{j}=2$, the same filtering/decimation scheme is utilized, but the unit-level scaling coefficients are the input to the filters. At the jth level, the inputs to the wavelet and scaling filters are the scaling coefficients from the previous $(j-1)$ level, and the outputs are the jth level wavelet and scaling coefficients.
} 
boundary coefficients ${ }^{7}$ at level $\mathrm{j}$ (provided that $\mathrm{n}_{\mathrm{j}}^{\prime}>\mathrm{L}_{\mathrm{j}}^{\prime}$ ), where $\mathrm{L}$ is the width of the wavelet filter. An unbiased estimator of the wavelet variance is defined as

$$
\tilde{v}_{X}^{2}\left(\tau_{j}\right) \equiv \frac{1}{\left(n_{j}^{\prime}-L_{j}^{\prime}\right) 2^{j}} \sum_{t=L_{j}^{\prime}-1}^{n_{j}^{\prime}-1} d_{j, t}^{2}
$$

Given that the DWT de-correlates the data, the non-boundary wavelet coefficients at a given level $\left(\mathbf{d}_{\mathrm{j}}\right)$ are zero-mean Gaussian white-noise processes.

Similarly, the unbiased wavelet covariance between time series $\mathrm{X}$ and $\mathrm{Y}$, at scale $\mathrm{j}$, can be defined as

$$
\tilde{v}_{X Y}^{2}\left(\tau_{j}\right) \equiv \frac{1}{\left(n_{j}^{\prime}-L_{j}^{\prime}\right) 2^{j}} \sum_{t=L_{j}^{\prime}}^{n_{j}^{\prime}-1} d_{j, t}^{(X)} d_{j, t}^{(Y)},
$$

provided that $\mathrm{n}_{\mathrm{j}}^{\prime}>\mathrm{L}_{\mathrm{j}}^{\prime}$.

However, as pointed out by Percival and Walden (2000), the sample properties of the DWT variance and covariance estimators are inferior to those of non-decimated discrete wavelet transforms, also known as stationary wavelet transforms. The non-decimated DWT is a non-orthogonal variant of the DWT, which is time-invariant. That is, unlike the classical DWT, the output is not affected by the date at which we start recording a time series. In addition, the number of coefficients at each scale equals the number of observations in the original time series. A non-decimated form of the DWT is known as the maximal overlap DWT (MODWT) ${ }^{8}$ The unbiased MODWT estimator of the wavelet variance is given by

$$
\hat{v}_{\mathrm{X}}^{2}\left(\tau_{\mathrm{j}}\right) \equiv \frac{1}{\mathrm{M}_{\mathrm{j}}} \sum_{\mathrm{t}=\mathrm{L}_{\mathrm{j}}-1}^{\mathrm{n}-1} \tilde{\mathrm{d}}_{\mathrm{j}, \mathrm{t}}^{2}
$$

where $\tilde{\mathrm{d}}_{\mathrm{j}, \mathrm{t}}^{2}$ is the MODWT-wavelet coefficient at level $\mathrm{j}$ and time $t, \mathrm{M}_{\mathrm{j}} \equiv \mathrm{n}-\mathrm{L}_{\mathrm{j}}+1$, $L_{j} \equiv\left(2^{j}-1\right)(L-1)+1$ is the width of the MODWT filter for level $j$, and $n$ is the number of observations in the original time series. While there are n MODWT-wavelet coefficients at each level $\mathrm{j}$, the first $\left(\mathrm{L}_{\mathrm{j}}-1\right)$-boundary coefficients are discarded. (Retaining such boundary coefficients leads to a biased estimate).

\footnotetext{
${ }^{7}$ The $\lfloor\mathrm{x}\rfloor$ and $\lceil\mathrm{x}\rceil$ terms represent the greatest integer $\leq \mathrm{x}$ and the smallest integer $\geq \mathrm{x}$, respectively. Boundary coefficients are those that are formed by combining together some values from the beginning and the end of the time series.

${ }^{8}$ The scaling $\left(\tilde{l}_{k}\right)$ and wavelet $\left(\tilde{h}_{k}\right)$ filter coefficients for the MODWT are rescaled versions of those of the DWT. Specifically, where $\tilde{\mathrm{l}}_{\mathrm{k}} \equiv \mathrm{l}_{\mathrm{k}} / \sqrt{2}$ and $\tilde{\mathrm{h}}_{\mathrm{k}} \equiv \mathrm{h}_{\mathrm{k}} / \sqrt{2}$.
} 

obtained as

Likewise, the unbiased MODWT estimator of the wavelet covariance can be

$$
\hat{v}_{\mathrm{XY}}^{2}\left(\tau_{\mathrm{j}}\right) \equiv \frac{1}{\mathrm{M}_{\mathrm{j}}} \sum_{\mathrm{t}=\mathrm{L}_{\mathrm{j}}^{\prime}}^{\mathrm{n}-1} \tilde{\mathrm{d}}_{\mathrm{j}, \mathrm{d}}^{(\mathrm{X})} \tilde{\mathrm{d}}_{\mathrm{j}, \mathrm{t}}^{(\mathrm{Y})}
$$

Let us now consider the slope estimates of equation (8). The MODWT-based slopes at scale $\mathrm{j}$ will be given by

$$
\hat{\beta}_{1 \mathrm{i}}\left(\tau_{\mathrm{j}}\right)=\frac{\hat{\delta}_{\mathrm{ri}_{\mathrm{i}} \mathrm{r}_{\mathrm{w}}^{*}}\left(\tau_{\mathrm{j}}\right)-\hat{\delta}_{\mathrm{r}_{\mathrm{i}} \mathrm{s}}\left(\tau_{\mathrm{j}}\right) \hat{\delta}_{\mathrm{sr}_{\mathrm{w}}^{*}}\left(\tau_{\mathrm{j}}\right)}{1-\hat{\delta}_{\mathrm{r}_{\mathrm{w}}^{*} \mathrm{~s}}\left(\tau_{\mathrm{j}}\right) \hat{\delta}_{\mathrm{sr}_{\mathrm{w}}^{*}}\left(\tau_{\mathrm{j}}\right)} \quad \hat{\beta}_{2 \mathrm{i}}\left(\tau_{\mathrm{j}}\right)=\frac{\hat{\delta}_{\mathrm{r}_{\mathrm{i}} \mathrm{s}}\left(\tau_{\mathrm{j}}\right)-\hat{\delta}_{\mathrm{r}_{\mathrm{i}} \mathrm{r}_{\mathrm{w}}^{*}}\left(\tau_{\mathrm{j}}\right) \hat{\delta}_{\mathrm{r}_{\mathrm{w}}^{*} \mathrm{~s}}\left(\tau_{\mathrm{j}}\right)}{1-\hat{\delta}_{\mathrm{r}_{\mathrm{w}}^{*} \mathrm{~s}}\left(\tau_{\mathrm{j}}\right) \hat{\delta}_{\mathrm{sr}_{\mathrm{w}}^{*}}\left(\tau_{\mathrm{j}}\right)}
$$

where $\hat{\delta}_{\mathrm{r}_{\mathrm{i}}{ }_{\mathrm{w}}^{*}}\left(\tau_{\mathrm{j}}\right)=\frac{\hat{v}_{\mathrm{r}_{\mathrm{i}} \mathrm{r}_{\mathrm{w}}^{*}}^{2}\left(\tau_{\mathrm{j}}\right)}{\hat{v}_{\mathrm{r}_{\mathrm{w}}^{*}}^{2}\left(\tau_{\mathrm{j}}\right)}, \hat{v}_{\mathrm{r}_{\mathrm{i}} \mathrm{r}_{\mathrm{w}}^{*}}^{2}\left(\tau_{\mathrm{j}}\right)$ is the MODWT-wavelet covariance of asset $\mathrm{i}$ and the world market portfolio at scale $\mathrm{j}$, and $\hat{\mathrm{v}}_{\mathrm{r}_{\mathrm{w}}^{*}}^{2}\left(\tau_{\mathrm{j}}\right)$ is the MODWT-wavelet variance of the world market portfolio at scale j. The other terms can be obtained in a similar fashion.

Likewise, the $\mathrm{R}^{2}$ at scale $\mathrm{j}$ can be defined as

$$
\mathrm{R}^{2}\left(\tau_{\mathrm{j}}\right)=\frac{\rho_{\mathrm{r}_{\mathrm{i}}^{*} \mathrm{w}_{\mathrm{w}}^{*}}^{2}\left(\tau_{\mathrm{j}}\right)+\rho_{\mathrm{r}_{\mathrm{i}} \mathrm{S}}^{2}\left(\tau_{\mathrm{j}}\right)-2 \rho_{\mathrm{ri}_{\mathrm{i}}^{*} \mathrm{w}_{\mathrm{w}}^{*}}\left(\tau_{\mathrm{j}}\right) \rho_{\mathrm{r}_{\mathrm{i}} \mathrm{S}}\left(\tau_{\mathrm{j}}\right) \rho_{\mathrm{r}_{\mathrm{w}}^{*} \mathrm{~s}}\left(\tau_{\mathrm{j}}\right)}{1-\rho_{\mathrm{r}_{\mathrm{w}}^{*} \mathrm{~s}}^{*}\left(\tau_{\mathrm{j}}\right)}
$$

where $\rho_{\mathrm{ri}_{\mathrm{i}} \mathrm{r}_{\mathrm{w}}^{*}}\left(\tau_{\mathrm{j}}\right)=\frac{\mathrm{v}_{\mathrm{r}_{\mathrm{i}} \mathrm{r}_{\mathrm{w}}^{*}}^{2}\left(\tau_{\mathrm{j}}\right)}{\sqrt{v_{\mathrm{r}_{\mathrm{i}}}^{2}\left(\tau_{\mathrm{j}}\right) \mathrm{v}_{\mathrm{r}_{\mathrm{w}}^{*}}^{2}\left(\tau_{\mathrm{j}}\right)}}$ is the wavelet-based correlation coefficient between $\mathrm{r}_{\mathrm{i}}$ and $r_{w}^{*}$ at scale $j$, etcetera.

\subsection{Wavelet-based Value at Risk (VaR)}

VaR is a popular measure of market risk (see, for example, Jorion 2001, chapter 1), whose origin dates back to the late 1980's at J.P. Morgan. In particular, VaR answers the question of how much we can lose, with a given probability, over a certain time horizon. In this section, we derive a time-scale decomposition of VaR.

In order to facilitate the presentation of the algebraic expressions, let us consider the following alternative representation of equation (8), in terms of two risk factors, for the return on a given asset of country $i, i=1, . . k$ :

$$
\mathrm{r}_{\mathrm{i}}=\beta_{0 \mathrm{i}}+\beta_{1 \mathrm{i}} \mathrm{F}_{1}+\beta_{2 \mathrm{i}} \mathrm{F}_{2 \mathrm{i}}+\varepsilon_{\mathrm{i}}
$$

where $F_{1}$ represents the return on the world market portfolio $\left(\mathrm{r}_{\mathrm{w}}^{*}\right)$, common to all assets, and $\mathrm{F}_{2 \mathrm{i}}$ is the exchange rate variation of the domestic currency against the foreign currency 
(i.e., US dollar). Under the assumption that the error terms are uncorrelated across countries, that is $\operatorname{cov}\left(\varepsilon_{\mathrm{i}}, \varepsilon_{\mathrm{j}}\right)=0 \forall \mathrm{i} \neq \mathrm{j}$, we can obtain the following expression for the covariance between returns $\mathrm{i}$ and $\mathrm{j}$ :

$$
\begin{aligned}
& \operatorname{cov}\left(\mathrm{r}_{\mathrm{i}}, \mathrm{r}_{\mathrm{j}}\right)=\beta_{1 \mathrm{i}} \beta_{1 \mathrm{j}} \operatorname{var}\left(\mathrm{F}_{1}\right)+\beta_{1 \mathrm{i}} \beta_{2 \mathrm{j}} \operatorname{cov}\left(\mathrm{F}_{1}, \mathrm{~F}_{2 \mathrm{j}}\right)+\beta_{1 \mathrm{j}} \beta_{2 \mathrm{i}} \operatorname{cov}\left(\mathrm{F}_{1}, \mathrm{~F}_{2 \mathrm{i}}\right)+\beta_{2 \mathrm{i}} \beta_{2 \mathrm{j}} \operatorname{cov}\left(\mathrm{F}_{2 \mathrm{i}}, \mathrm{F}_{2 \mathrm{j}}\right) \\
&+\operatorname{cov}\left(\varepsilon_{\mathrm{i}}, \varepsilon_{\mathrm{j}}\right)
\end{aligned}
$$

where $\operatorname{cov}\left(\varepsilon_{\mathrm{i}}, \varepsilon_{\mathrm{j}}\right)=\left\{\begin{array}{rr}\sigma_{\varepsilon_{\mathrm{i}}}^{2} & \mathrm{i}=\mathrm{j} \\ 0 & \mathrm{i} \neq \mathrm{j}\end{array}\right.$.

Let us define $\sigma_{1}^{2}=\operatorname{var}\left(F_{1}\right), \quad \sigma_{2}^{i i}=\operatorname{var}\left(F_{2 i}\right), \quad \sigma_{2}^{i j}=\operatorname{cov}\left(F_{2 i}, F_{2 j}\right), \quad \sigma_{12}^{i i}=\operatorname{cov}\left(F_{1}, F_{2 i}\right)$, $\sigma_{12}^{\mathrm{jj}}=\operatorname{cov}\left(\mathrm{F}_{1}, \mathrm{~F}_{2 \mathrm{j}}\right)$, and let $\omega_{\mathrm{i}}$ be the share of country index ' $\mathrm{i}$ ' in the portfolio. The variance of the portfolio, measured in foreign currency, is given by

$$
\begin{gathered}
\sigma_{p}^{2}=\operatorname{var}\left(\sum_{i=1}^{k} \omega_{i}\left(r_{i}-F_{2 i}\right)\right)=\sum_{i=1}^{k} \sum_{j=1}^{k} \omega_{i} \omega_{j} \operatorname{cov}\left(r_{i}-F_{2 i}, r_{j}-F_{2 j}\right) \\
=\left(\sum_{i=1}^{k} \sum_{j=1}^{k} \omega_{i} \omega_{j} \beta_{1 i} \beta_{1 j}\right) \sigma_{1}^{2}+\sum_{i=1}^{k} \sum_{j=1}^{k} \omega_{i} \omega_{j} \widetilde{\beta}_{2 i} \widetilde{\beta}_{2 j} \sigma_{2}^{i i}+\sum_{i=1}^{k} \sum_{j=1}^{k} \omega_{i} \omega_{j}\left(\beta_{1 i} \widetilde{\beta}_{2 j} \sigma_{12}^{j j}+\widetilde{\beta}_{2 i} \beta_{1 j} \sigma_{12}^{i i}\right)+\sum_{i=1}^{k} \omega_{i}^{2} \sigma_{\varepsilon_{i}}^{2}
\end{gathered}
$$

where $\widetilde{\beta}_{2 \mathrm{i}} \equiv \beta_{2 \mathrm{i}}-1$.

For an equally-weighted portfolio of $\mathrm{k}$ assets, such that $\omega_{\mathrm{i}}=1 / \mathrm{k} \forall \mathrm{i}$, the variance of the portfolio can be succinctly expressed, in matrix form, as

$$
\sigma_{\mathrm{p}}^{2}=\frac{1}{\mathrm{k}^{2}}\left(\sigma_{1}^{2}\left(\boldsymbol{\beta}_{1}^{\prime} \mathbf{t}\right)^{2}+\tilde{\boldsymbol{\beta}}_{2}^{\prime} \boldsymbol{\Omega}_{\mathrm{F}_{2}} \tilde{\boldsymbol{\beta}}_{2}+\mathbf{t}^{\prime}\left(\boldsymbol{\beta}_{1}^{\prime} \tilde{\boldsymbol{\beta}}_{2}+\tilde{\boldsymbol{\beta}}_{2}^{\prime} \boldsymbol{\beta}_{1}\right) \boldsymbol{\Omega}_{\mathrm{F}_{1} \mathrm{~F}_{2}}+\sigma_{\varepsilon}^{\prime} \boldsymbol{\sigma}_{\varepsilon}\right)
$$

where $\boldsymbol{\Omega}_{\mathrm{F}_{2}}=\left(\begin{array}{cccc}\sigma_{2}^{11} & \sigma_{2}^{12} & \ldots & \sigma_{2}^{1 \mathrm{k}} \\ \sigma_{2}^{21} & \sigma_{2}^{22} & \ldots & \sigma_{2}^{2 \mathrm{k}} \\ \vdots & \vdots & \ddots & \vdots \\ \sigma_{2}^{\mathrm{k} 1} & \sigma_{2}^{\mathrm{k} 2} & \cdots & \sigma_{2}^{\mathrm{kk}}\end{array}\right), \boldsymbol{\beta}_{1}=\left(\begin{array}{c}\beta_{11} \\ \beta_{12} \\ \vdots \\ \beta_{1 \mathrm{k}}\end{array}\right), \tilde{\boldsymbol{\beta}}_{2} \cong\left(\begin{array}{c}\tilde{\beta}_{21} \\ \widetilde{\beta}_{22} \\ \vdots \\ \tilde{\beta}_{2 \mathrm{k}}\end{array}\right), \mathbf{l}=\left(\begin{array}{c}1 \\ 1 \\ \vdots \\ 1\end{array}\right), \boldsymbol{\Omega}_{\mathrm{F}_{1} \mathrm{~F}_{2}}=\left(\begin{array}{c}\sigma_{12}^{11} \\ \sigma_{12}^{22} \\ \vdots \\ \sigma_{12}^{\mathrm{kk}}\end{array}\right)$, and $\boldsymbol{\sigma}_{\varepsilon}=\left(\begin{array}{c}\sigma_{\varepsilon_{1}} \\ \sigma_{\varepsilon_{2}} \\ \vdots \\ \sigma_{\varepsilon_{\mathrm{k}}}\end{array}\right)$

Then the value at risk at the (1- $\alpha)$-percent confidence level, expressed in units of the foreign currency, for an equally-weighted portfolio is given by 


$$
\operatorname{VaR}(\alpha)=\mathrm{V}_{0} \kappa(\alpha) \sigma_{p}
$$

where $V_{0}$ is the initial investment, expressed in foreign currency, $\kappa(\alpha) \equiv \Phi^{-1}(1-\alpha)$, where $\Phi($.$) is the cumulative distribution function of the standard normal, and \sigma_{\mathrm{p}}$ is the square root of the portfolio variance in (27).

Based on expression (28), we define the (1- $\alpha)$-confidence level value at risk, at scale $\mathrm{j}$, as follows

$$
\operatorname{VaR}^{\left(\tau_{\mathrm{j}}\right)}(\alpha)=\mathrm{V}_{0} \kappa(\alpha) \sigma_{\mathrm{p}}{ }^{\left(\tau_{\mathrm{j}}\right)}
$$

where

$$
\begin{aligned}
& \sigma_{\mathrm{p}}{ }^{\left(\tau_{j}\right)}=\frac{1}{\mathrm{k}} \sqrt{\sigma_{1}^{2\left(\tau_{j}\right)}\left(\boldsymbol{\beta}_{1}{ }^{\left(\tau_{j}\right)^{\prime}} \mathbf{l}\right)^{2}+\tilde{\boldsymbol{\beta}}_{2}{ }^{\left(\tau_{j}\right)^{\prime}} \boldsymbol{\Omega}_{\mathrm{F}_{2}}{ }^{\left(\tau_{j}\right.} \tilde{\boldsymbol{\beta}}_{2}{ }^{\left(\tau_{j}\right)}+\mathbf{l}^{\prime}\left(\boldsymbol{\beta}_{1}{ }^{\left(\tau_{j}\right)^{\prime}} \tilde{\boldsymbol{\beta}}_{2}{ }^{\left(\tau_{j}\right)}+\tilde{\boldsymbol{\beta}}_{2}{ }^{\left(\tau_{j}\right)}{ }^{\prime}{ }_{1}{ }^{\left(\tau_{j}\right)}\right) \boldsymbol{\Omega}_{\mathrm{F}_{1} \mathrm{~F}_{2}}{ }^{\left(\tau_{j}\right)}+\boldsymbol{\sigma}_{\varepsilon}{ }_{\varepsilon}^{\left(\tau_{j}\right)^{\prime}} \boldsymbol{\sigma}_{\varepsilon}{ }^{\left(\tau_{j}\right)}} \\
& \boldsymbol{\Omega}_{\mathrm{F}_{2}}{ }^{\left(\tau_{\mathrm{j}}\right)}=\left(\begin{array}{cccc}
\sigma_{2}^{11}\left(\tau_{\mathrm{j}}\right) & \sigma_{2}^{12}\left(\tau_{\mathrm{j}}\right) & \ldots & \sigma_{2}^{1 \mathrm{k}}\left(\tau_{\mathrm{j}}\right) \\
\sigma_{2}^{21}\left(\tau_{\mathrm{j}}\right) & \sigma_{2}^{22}\left(\tau_{\mathrm{j}}\right) & \ldots & \sigma_{2}^{2 \mathrm{k}}\left(\tau_{\mathrm{j}}\right) \\
\vdots & \vdots & \ddots & \vdots \\
\sigma_{2}^{\mathrm{k} 1}\left(\tau_{\mathrm{j}}\right) & \sigma_{2}^{\mathrm{k} 2}\left(\tau_{\mathrm{j}}\right) & \cdots & \sigma_{2}^{\mathrm{kk}}\left(\tau_{\mathrm{j}}\right)
\end{array}\right), \quad \boldsymbol{\beta}_{1}{ }^{\left(\tau_{\mathrm{j}}\right)}=\left(\begin{array}{c}
\beta_{11}\left(\tau_{\mathrm{j}}\right) \\
\beta_{12}\left(\tau_{\mathrm{j}}\right) \\
\vdots \\
\beta_{1 \mathrm{k}}\left(\tau_{\mathrm{j}}\right)
\end{array}\right), \quad \tilde{\boldsymbol{\beta}}_{2}^{\left(\tau_{\mathrm{j}}\right)}=\left(\begin{array}{c}
\tilde{\beta}_{21}\left(\tau_{\mathrm{j}}\right) \\
\tilde{\beta}_{22}\left(\tau_{\mathrm{j}}\right) \\
\vdots \\
\tilde{\beta}_{2 \mathrm{k}}\left(\tau_{\mathrm{j}}\right)
\end{array}\right), \\
& \boldsymbol{\Omega}_{\mathrm{F}_{1} \mathrm{~F}_{2}}{ }^{\left(\tau_{\mathrm{j}}\right)}=\left(\begin{array}{c}
\sigma_{12}^{11}\left(\tau_{\mathrm{j}}\right) \\
\sigma_{12}^{22}\left(\tau_{\mathrm{j}}\right) \\
\vdots \\
\sigma_{12}^{\mathrm{kk}}\left(\tau_{\mathrm{j}}\right)
\end{array}\right) \text {, and } \boldsymbol{\sigma}_{\varepsilon}{ }^{\left(\tau_{\mathrm{j}}\right)}=\left(\begin{array}{c}
\sigma_{\varepsilon_{1}}\left(\tau_{\mathrm{j}}\right) \\
\sigma_{\varepsilon_{2}}\left(\tau_{\mathrm{j}}\right) \\
\vdots \\
\sigma_{\varepsilon_{\mathrm{k}}}\left(\tau_{\mathrm{j}}\right)
\end{array}\right) \text {. }
\end{aligned}
$$

and $\quad \sigma_{1}^{2}\left(\tau_{\mathrm{j}}\right)=v_{\mathrm{F}_{1}}^{2}\left(\tau_{\mathrm{j}}\right), \quad \sigma_{2}^{\mathrm{ii}}\left(\tau_{\mathrm{j}}\right)=v_{\mathrm{F}_{2 \mathrm{i}}}^{2}\left(\tau_{\mathrm{j}}\right), \quad \sigma_{2}^{\mathrm{ij}}\left(\tau_{\mathrm{j}}\right)=v_{\mathrm{F}_{2 \mathrm{i}} \mathrm{F}_{2 \mathrm{j}}}^{2}\left(\tau_{\mathrm{j}}\right), \quad \sigma_{12}^{\mathrm{ii}}\left(\tau_{\mathrm{j}}\right)=v_{\mathrm{F}_{1} \mathrm{~F}_{2 \mathrm{j}}}^{2}\left(\tau_{\mathrm{j}}\right)$, $i, j=1, \ldots, k$. The variance of the error term for asset $i$, at scale $j$, can be obtained from equation (25) as $\sigma_{\varepsilon_{\mathrm{i}}}^{2}\left(\tau_{\mathrm{j}}\right)=v_{\mathrm{r}_{\mathrm{i}}}^{2}\left(\tau_{\mathrm{j}}\right)-\beta_{1 \mathrm{i}}^{2}\left(\tau_{\mathrm{j}}\right) \mathrm{v}_{\mathrm{F}_{1}}^{2}\left(\tau_{\mathrm{j}}\right)-\beta_{2 \mathrm{i}}^{2}\left(\tau_{\mathrm{j}}\right) v_{\mathrm{F}_{2 \mathrm{i}}}^{2}\left(\tau_{\mathrm{j}}\right)-2 \beta_{1 \mathrm{i}}\left(\tau_{\mathrm{j}}\right) \beta_{2 \mathrm{i}}\left(\tau_{\mathrm{j}}\right) \mathrm{v}_{\mathrm{F}_{\mathrm{i}} \mathrm{F}_{\mathrm{i}}}^{2}\left(\tau_{\mathrm{j}}\right)$.

The above formula allow us to obtain an expression for the marginal VaR, which is defined as (see, for instance, Jorion, 2001, chapter 7)

$$
\Delta \mathrm{VaR}_{\mathrm{i}}=\frac{\partial \mathrm{VaR}}{\partial \omega_{\mathrm{i}}} \frac{1}{\mathrm{~V}_{0}}=\kappa(\alpha) \frac{1}{2 \sigma_{\mathrm{p}}} \frac{\partial \sigma_{\mathrm{p}}^{2}}{\partial \omega_{\mathrm{i}}}
$$

where $\omega_{\mathrm{i}}$ is the share of asset $\mathrm{i}$ in the portfolio.

The marginal VaR quantifies the change in the portfolio value resulting from taking an additional dollar exposure to a given asset of country $i$ in the portfolio. From expression (26) and for an equally-weighted portfolio, we have: 


$$
\frac{\partial \sigma_{p}^{2}}{\partial \omega_{i}}=\frac{1}{k}\left(\left(\sum_{j=1}^{k} \beta_{1 j} \sigma_{1}^{2}+\sum_{j=1}^{k} \tilde{\beta}_{2 j} \sigma_{12}^{\mathrm{jj}}\right) \beta_{1 \mathrm{i}}+\left(\sum_{\mathrm{j}=1}^{\mathrm{k}} \tilde{\beta}_{2 \mathrm{j}} \sigma_{2}^{\mathrm{ii}}+\sum_{\mathrm{j}=1}^{\mathrm{k}} \beta_{1 \mathrm{j}} \sigma_{12}^{\mathrm{ii}}\right) \tilde{\beta}_{2 \mathrm{i}}+2 \sigma_{\varepsilon_{\mathrm{i}}}^{2}\right)
$$

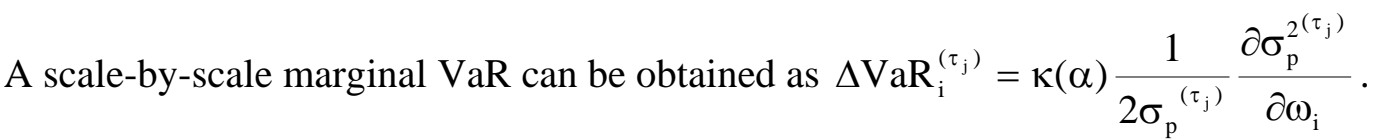

\section{Empirical results}

\subsection{Description of the data}

Data on stock indices of seven emerging countries-Brazil, Chile, Mexico, Indonesia, South Korea, Malaysia, and Thailand-in both local and US currency was obtained from Morgan Stanley. In addition, two proxies of the world market portfolio were considered: the Emerging Markets and the World Indices, both of which are measured in US dollars and constructed by Morgan Stanley. The Emerging Markets Index is a free float-adjusted market capitalization index that consists of 26 emerging market country indices, whereas the World Index is a free float-adjusted market capitalization index that consists of 23 developed market country indices. The sample period spans from 1990 to 2004, and returns are measured at a daily frequency. The exchange rate variation is constructed from the daily returns in local currency and US dollar. In particular, given that returns are computed in logarithms, the daily exchange rate variation is obtained as the difference between the return in local currency and the return in US dollars.

Table 1 shows descriptive statistics of returns in local currency for each country in the sample, the exchange-rate variation of each country's currency-expressed in units of local currency per US dollar-, and statistics of daily returns of the two proxies of the world market portfolio. As we see, exchange rates stand out for their asymmetry and high kurtosis. In particular, the most extreme values occurred around the Asian crisis, particularly for Indonesia, Malaysia and South Korea. Very high volatility of Asian stock markets was also observed around the same period. The range, a very simple measure of dispersion, shows that in the sample period the most volatile stock markets were those of Brazil and Malaysia, whereas the most volatile exchange rate markets were those of Indonesia and Malaysia. In contrast, Chile stood out as one of the countries with the lowest volatility in both the stock and exchange rate markets.

\subsection{Estimates of sensitivities to risk factors}

We use two approaches to estimating the parameters of the international CAPM (ICAPM). One of them consists of obtaining parameter estimates by linear regression analysis applied to the recomposed-DWT crystals of each time scale. This is the procedure that has been commonly used in empirical applications of wavelet analysis (e. g, Ramsey and Lampart 1998; Norsworthy, Li, and Gorener 2000; Gençay, Selçuk, and Whitcher 2002, chapter 4). Ramsey (1999) carries out a sampling analysis of distributional properties of regression-parameter estimates in the context of time-scale decomposition. He concludes that slopes coefficients at the trend and oscillatory components of the data behave like Gaussian random variables. In addition, Ramsey finds that the level of correlation between 
regressions coefficients estimates is very low across time scales. These two results are important because we can rely on the statistical machinery of linear-regression models.

The second approach we use is one based on wavelet-variance analysis, which determines estimates for the slopes and the goodness of fit of the model $\left(R^{2}\right)$ by the MODWT-variance and covariance formulas presented in Section 2.3. In what follows, we will refer to the estimates obtained using the first approach as "regression-based", whereas the estimates from the second approach will be labeled as "MODWT-based".

In order to obtain the regression-based estimates, we first compute the multiresolution decomposition (MRD) of each time series, namely, the return on the country index, the return on the proxy of the world market portfolio, and the return on the exchange rate of the domestic currency against the US dollar. We then run linear regressions of the recomposed crystals - that is, the time-series reconstructed from the crystals-for each time scale. The MRD of each time series is computed using the discrete-wavelet transform (DWT), so that the recomposed crystals are orthogonal across scales.

Figure 1 depicts MRD for the returns on the Thai index (in local currency) and the exchange rate of the Thai baht against the US dollar. As we see, most variation of the original return series (which are labeled as "sum") is captured at the first three scales. That is, at a 2-16 day horizon. Specifically, for the exchange rate return the energy contained at scales 1-3 is 85.7 percent, whereas for the return on the domestic index, it reaches 83.1 percent. $^{9}$

Panels (a) and (b) of Tables 2 show our regression-based estimates for each proxy of the world market portfolio: the Emerging Markets and World MSCI indices. Countries' sensitivities to the world market portfolio and the exchange rate of the domestic currency against the US dollar are reported for the raw data and for scales 1 through 6 (i.e., 2-128 day dynamics). In Panel (a), we observe that the country with the greatest sensitivity to the world market portfolio (Emerging Markets Index) in the raw data is Brazil, followed by South Korea and Thailand. All countries, except for Brazil, have a positive slope on the exchange-risk factor in the raw data (for Chile, the slope is statistically insignificant). In other words, the performance of the Brazilian stock market is inversely correlated with a depreciation of the real against the US dollar. In other words, Brazilian stocks behave, on average, like a hedge for a depreciating real. The same phenomenon is observed at scales 13 and 5-6, being the negative correlation strongest at scale 6 . That is, at the trendcomponent of the time series.

Chile's stock index shows no sensitivity to the exchange rate variation at the 2-8 day horizon, but, similarly to Brazil, exhibits an inverse correlation with it at scales 5 and 6 . A similar pattern to Chile's is that observed for Mexico. By contrast, the Asian stock indices tend to exhibit a more homogeneous behavior with respect to the exchange rate-risk factor

\footnotetext{
9 The energy in a given crystal is calculated as the sum of squares of all of its elements over the sum of squares of all observations in the original time series. One appealing characteristic of the DWT is that it is an energy preserving transform. This means that the energy in all the DWT coefficients equals the energy in the original time series. (This also holds for the MODWT).
} 
across scales. Indeed, at almost all scales, the country indices exhibit a positive and statistically significant exposure to exchange-rate risk. A graphical representation of the linear models being estimated at different time scales is depicted in Figure 2 for Thailand.

With respect to market risk, sensitivities tend to be higher at the upper scales of the data, particularly for both scales 5 and 6. In addition, the good-of-fit of the regression models $\left(\mathrm{R}^{2}\right)$ reaches its peak at either scale 5 or 6 , depending on the country. In other words, the predictions of our ICAPM tend to be more meaningful for a medium- or longterm horizon. A similar conclusion is reached by Gencay at al. $(2003,2005)$ for the singlecountry CAPM.

In Panel (b) of Table 2, we have estimation results when using the World Index as a proxy for the world market portfolio. We observe, in general, that the country indices exhibit less sensitivity to market risk, but more and positive sensitivity to exchange-rate risk. An exception is Mexico, whose stock market appears to be more integrated with those of the developed countries comprising the MSCI World index. For instance, at scale 5, the beta on the world market portfolio reaches its peak at 1.02. In turn, Brazil's stock market performance is again inversely correlated with the exchange rate variation in the raw data, but to a lesser extent than in Panel (a). At scales 1-3 and 5, the slope on the exchange-rate risk is small and statistically insignificant, whereas at scale 4 it is both positive and statistically significant. Only at scale 6, does the sensitivity to exchange-rate risk show the same negative sign observed in the raw data.

With respect to the good-of-fit of the ICAPM, the $\mathrm{R}^{2}$ are in general substantially lower than those reported in Panel (a). This finding suggests that the Emerging Markets index is a more suitable approximation to the world market portfolio than the World Index. As noted earlier, this seems indicative of a lower degree of stock market integration of the sampled countries with those of the countries comprising the World Index.

Table 3, Panels (a) and (b), shows the estimates using the MODWT variancecovariance analysis described in Section 2.3. As we see, we can draw similar conclusions to the ones reported above. However, the magnitudes of the estimates differ, particularly so for the upper scales 4-6. This is not surprising for two reasons. First, the regression-based estimates are obtained from recomposed crystals, where the quality of reconstruction will affect the accuracy of the parameter estimates. Second, the DWT has practical limitations when compared with non-decimated wavelet transforms, as previously discussed. Interestingly, the $\mathrm{R}^{2}$ yielded by the two methods are very similar in all cases.

In order to further investigate how the magnitude of the parameter estimates are affected by the method utilized, we aggregated time scales to reduce the reconstruction error of the DWT. Tables 4 and 5 report our results. Scales 1-2 measure the dynamics of returns over 2-8 days, whereas scales 1-4, the dynamics over 2-32 days. As mentioned earlier, most variation in returns is captured at the three first scales. Panel (a) of Table 4 shows reports the estimation results when the proxy of the world market portfolio is the Emerging Markets Index. Our conclusions are similar to those reported before: Brazil exhibits high market risk and the performance of its stock market is inversely correlated with the variation of the real/US dollar parity. Both Chile and Mexico's stock indices present comparatively little sensitivity to exchange market risk and more moderate market 
risk. Among Asian countries, South Korea exhibits the highest market and exchange risks (scales 1-2 and scales 1-4, respectively). When looking at the MODWT estimates of Panel (a) of Table 5, we see that the magnitudes of the estimated slopes are almost identical to the regression-based estimates of Table 4. Clearly, the discrepancies between the two methods are more noticeably at scales 1-2, given that at scales 1-4 most of the variation (energy) of the original return series is captured by the recomposed crystals.

Panels (b) of Tables 4 and 5 report analogous results when using the Word Index as a proxy of the world market portfolio. As we concluded earlier, all indices at scales 1-2 and scales 1-4 present lower sensitivity to the World than to the Emerging Market index, with the exception of Mexico. In particular, at scales 1-2, both Indonesia and Malaysia presents low sensitivity to market risk. In general, Asian countries display higher sensitivities to exchange rate than to market risk when using the World Index. It is worth noticing that at scales 1-2, the stock indices of Latin American countries have greater slopes on the World index than those of the Asian countries. In other words, the former appear as relatively more integrated with developed markets than the latter.

\subsection{Value at Risk estimations}

One application of the time-scale decomposition of returns is to quantify the value at risk (VaR) of a portfolio for different investment horizons. Table 6 presents 95-percent VaR estimates for both proxies of the world market portfolio. We assume an equallyweighted portfolio - whose value is measured in US dollars - comprised by the seven country indices. We report VaR estimates for the raw data and for different time scales, using both the regression-based and the MODWT estimates of risk-factor sensitivities and variance-covariance matrices of risk factors. If we invested US $\$ 100$, we have that, with a 95-percent confidence level, our portfolio loss in one day would be less than or equal to US\$2.25, for the raw data, when using the Emerging Markets (EM) index as the proxy of the world market portfolio. Such a potential loss declines to US\$1.85 when the world market portfolio is the World Index.

When decomposing the data into time scales, we see that potential losses are greater at shorter-time horizons (i.e., higher frequencies of the data). For instance, at scale 1 (i.e., 2-4 days), the 95-percent VaR is US\$1.33 and US\$1.34 in one day for the MODWT and regression-based estimates, respectively, when using the EM index as the proxy of the world market portfolio. Such figures drop to \$1.095 and \$1.1, respectively, when using the World index. By contrast, at the lower frequencies of the stock indices (i.e., trend component), potential daily losses substantially decrease. For instance, at scale 6 (i.e., 64128 days), the MODWT estimate of the 95-percent VaR is only US\$0.386 per day, when using the EM index as the proxy of the world market portfolio, and US $\$ 0.341$ per day, when using the World index. Such findings are confirmed when aggregating time scales. For instance, at scales 1-4 (i.e., 2-32 days), the 95-percent daily VaR is relatively close to that for the raw data. In other words, the contribution of the upper time scales to risk is relatively marginal.

Finally, Panels (a) and (b) of Table 7 present estimates of 95-percent marginal VaR for each country in the sample, for the raw data and for scales 1 through 6 , using both 
proxies of the world market portfolio. For the sake of brevity, we only present estimates based on the MODWT procedure. (Regression-based estimates are roughly equal). In general, we see that the countries that contribute the most to risk are Brazil, Mexico, and Indonesia. For instance for the raw data, Panel (a) — where the EM index is the proxy of the world market portfolio-shows that if we increased our exposure to the Brazilian index in US\$1, the VaR would rise in 2.4 cents in one day, at the 95 confidence level. Moreover, we see that at higher frequencies of the data, the marginal VaR is greatest. For instance, for the Brazilian index, Panel (a) shows that the marginal VaR amounts to 1.6 cents for scale 1, but to only 0.3 cents at scale 6 .

\section{Conclusions}

In this article, we concentrated on a wavelet-based international asset pricing model (ICAPM). Previous studies have stressed the importance of exchange rate risk, given that in practice there can be considerable departures from the purchasing power parity. From a parsimonious ICAPM, which postulates that an investment in a country portfolio is subject to two sources of risk, namely, the country index's sensitivity to a global portfolio and the performance of the domestic currency relative to the foreign currency, we derive an analytical formula for time-scale value at risk and marginal value at risk (VaR) of a portfolio.

We apply our methodology to stock indices of seven emerging economies belonging to Latin America and Asia-namely, Brazil, Chile, Mexico, Indonesia, South Korea, Malaysia, and Thailand. Our main conclusions can be summarized as follows. First, the estimation results depend upon the choice of the world market portfolio. In particular, the stock markets of the sampled countries appear to be more integrated with other emerging countries than with developed ones. Second, value at risk depends on the time horizon we consider. In the short run, potential losses are greater than in the long run. Third, some stock indices are more likely to cause portfolio losses than others. In particular, both Brazil and Indonesia appear as risky investments whereas both Chile and Malaysia, as safe.

\section{References}

Adler, M., and B. Dumas, 1983, International portfolio choice and corporate finance: A synthesis, Journal of Finance 38(3), 925-984.

Bollerslev, T., Engle, R., Wooldridge, J., 1988. A Capital-Asset Pricing Model with TimeVarying Covariances. Journal of Political Economy 96, 116-131.

Connor, J., and R. Rossiter, 2005. Wavelet Transforms and Commodity Prices. Studies in Nonlinear Dynamics \& Econometrics 9(1). Article 6, 20 pages.

Copeland, T., Weston, J., Shastri, K., 2004. Financial Theory and Corporate Policy. Fourth edition. Pearson Addison Wesley.

De Santis, G., and G. Bruno, 1998. How big is the risk premium for currency risk? Journal of Financial Economics 49, 375-412. 
Dumas, B., 1994. A Test of the International CAPM Using Business Cycles Indicators as Instrumental Variables. In The Internationalization of Equity Markets, Jeffrey A. Frankel ed., pp. 23-50, (Chicago: University of Chicago Press).

Finance 2, 445-479.

and B. Solnik, 1995. The world price of foreign exchange risk, Journal of

Engle R., Lilien, D., Robins, R., 1987. Estimating Time-Varying Risk Premia in the Term Structure: the ARCH-M Model. Econometrica 55, 391-407.

Fama, E., French, K., 1992. The Cross-section of Expected Returns. Journal of Finance 47, 427-465.

Gençay, R., Whitcher, B., Selçuk, F., 2001. Differentiating Intraday Seasonalities through Wavelet Multi-Scaling. Physica A, 289, 543-556.

, 2002. An Introduction to Wavelets and Other

Filtering Methods in Finance and Economics. Academic Press, San Diego.

2003. Systematic Risk and Time Scales.

Quantitative Finance 3, 108-116.

International Money and Finance 24(1), 55-70.

2005. Multiscale Systematic Risk. Journal of

Johnston, J., 1984. Econometric Methods. Third edition. McGraw-Hill.

Jorion, P., 2001. Value at Risk: The New Benchmark for Managing Financial Risk. McGraw Hill, second edition.

Karuppiah, J., Los, C., 2005. Wavelet multiresolution analysis of high-frequency Asian FX rates, Summer 1997. International Review of Financial Analysis 14(2), 211-246. Quantitative Issues in Finance

Kothari, S., Shanken, J., 1998. On defense of beta, in: J. Stern and D. Chew (Eds.), The Revolution in Corporate Finance, third edition. Blackwell Publishers Inc., pp. 52-57.

Lin, Shinn-Juh, Stevenson, M., 2001. Wavelet Analysis of the Cost-of-Carry Model. Studies in Nonlinear Dynamics \& Econometrics 5(1), 87-102.

Megginson, W., 1997. Corporate Finance Theory. Addison-Wesley Educational Publishers Inc.

Norsworthy J., Li, D., Gorener, R., 2000. Wavelet-Based Analysis of Time Series: An Export from Engineering to Finance. Manuscript presented at the 2000 IEEE International Engineering Management Society Conference. 
Percival, D., Walden, A., 2000. Wavelets Analysis for Time Series Analysis. Cambridge University Press, Cambridge, U.K.

Ramsey, J., Usikov, D., Zaslavsky, G., 1995. An Analysis of US Stock Price Behavior using Wavelets. Fractals 3, 377-389.

Ramsey, J., Zhang, Z., 1996. The Application of Waveform Dictionaries to Stock Market Data, in: Kravstov, Y.A, Kadtke, J.B. (Eds.), Predictability of Dynamical Systems, Vol. 69. Springer Verlag, New York, pp. 189-205.

Waveform Dictionaries. Journal of Empirical Finance, 4, 341-372.

Ramsey J., Lampart, C., 1998. The Decomposition of Economic Relationships by Time Scale Using Wavelets: Expenditure and Income. Studies in Nonlinear Dynamics \& Econometrics 3(1), 23-42.

Ramsey, J., 1999. Regression over Timescale Decompositions: A Sampling Analysis of Distributional Properties. Economic Systems Research 11(2), 163-183.

Ramsey, J., 2002. Wavelets in Economics and Finance: Past and Future. Studies in Nonlinear Dynamics \& Econometrics 6(3), 1-29.

Sercu, P., and Uppal, R., 1995. International Financial Markets and the Firm. SouthWestern College Publishing.

Solnik, B. 1974. The International Pricing of Risk: An Empirical Investigation of the World Capital Structure. Journal of Finance 29(2), 365-378.

Stulz, R., 1981. A model of international asset pricing, Journal of Financial Economics 9, 383-406.

1992. International portfolio choice and asset pricing: An integrative survey.

Working paper, Ohio State University.

Whitcher, B., 2004. Wavelet-Based Estimation for Seasonal Long-Memory Processes. Technometrics 46 (2), 225-238. 


\section{Tables}

Table 1 Descriptive statistics of stock returns and exchange rate variation: 1990-2004

Country index returns in local currency

\begin{tabular}{|c|c|c|c|c|c|c|c|c|c|}
\hline & Mean & Std. Dev & Minimum & Maximum & Range & Skewness & Kurtosis & Q1 & Q3 \\
\hline Chile & 0.00 & 0.01 & -0.06 & 0.09 & 0.15 & 0.23 & 3.95 & -0.01 & 0.01 \\
\hline Indonesia & 0.00 & 0.02 & -0.19 & 0.17 & 0.36 & 0.10 & 13.27 & -0.01 & 0.01 \\
\hline South Korea & 0.00 & 0.02 & -0.13 & 0.11 & 0.25 & 0.15 & 3.36 & -0.01 & 0.01 \\
\hline Thailand & 0.00 & 0.02 & -0.10 & 0.21 & 0.32 & 0.87 & 9.17 & -0.01 & 0.01 \\
\hline \multicolumn{10}{|c|}{ Exchange rate variation against the US dollar } \\
\hline & Mean & Std. Dev & Minimum & Maximum & Range & Skewness & Kurtosis & Q1 & Q3 \\
\hline Brazil & 0.00 & 0.01 & -0.15 & 0.12 & 0.27 & -1.67 & 27.15 & -0.01 & 0.00 \\
\hline South Korea & 0.00 & 0.01 & -0.14 & 0.20 & 0.33 & 0.87 & 159.89 & 0.00 & 0.00 \\
\hline Malaysia & 0.00 & 0.01 & -0.36 & 0.19 & 0.55 & -13.58 & 860.92 & 0.00 & 0.00 \\
\hline Thailand & 0.00 & 0.01 & -0.07 & 0.06 & 0.13 & -0.48 & 39.47 & 0.00 & 0.00 \\
\hline \multicolumn{10}{|c|}{ MSCI Global index returns in US dollars } \\
\hline & Mean & Std. Dev & Minimum & Maximum & Range & Skewness & Kurtosis & Q1 & Q3 \\
\hline Emerging Markets & 0.00 & 0.01 & -0.07 & 0.06 & 0.14 & -0.52 & 4.09 & 0.00 & 0.01 \\
\hline World & 0.00 & 0.01 & -0.05 & 0.05 & 0.10 & -0.09 & 3.21 & 0.00 & 0.00 \\
\hline
\end{tabular}

Observations $\quad 3,824$

Notes: (1) The data were obtained from Morgan Stanley. (2) Stock index returns and exchange rate variations are measure at a daily frequency. (3) Q1 and Q3 stand for the first and third quartile, respectively. (4) The range is a measure of dispersion that is calculated as the difference between the maximum and the minimum. (5) The MSCI Emerging Markets Index is a free float-adjusted market capitalization index that is designed to measure equity market performance in the global emerging markets. The MSCI Emerging Markets Index consists of the following 26 emerging market country indices: Argentina, Brazil, Chile, China, Colombia, Czech Republic, Egypt, Hungary, India, Indonesia, Israel, Jordan, Korea, Malaysia, Mexico, Morocco, Pakistan, Peru, Philippines, Poland, Russia, South Africa, Taiwan, Thailand, Turkey and Venezuela. In turn, the MSCI World Index is a free float-adjusted market capitalization index that is designed to measure global developed market equity performance. The MSCI World Index consists of the following 23 developed market country indices: Australia, Austria, Belgium, Canada, Denmark, Finland, France, Germany, Greece, Hong Kong, Ireland, Italy, Japan, Netherlands, New Zealand, Norway, Portugal, Singapore, Spain, Sweden, Switzerland, the United Kingdom and the United States. 
Table 2 Regression-based estimates of international CAPM

(a) World market portfolio is the Emerging Markets MSCI Index

\begin{tabular}{|c|c|c|c|c|c|c|c|c|}
\hline & & Brazil & Chile & Mexico & Indonesia & Korea & Malaysia & Thailand \\
\hline \multirow[t]{5}{*}{ Raw data } & $\hat{\beta}_{1}$ & 1.50 & 0.45 & 0.81 & 0.47 & 0.93 & 0.65 & 0.87 \\
\hline & $\hat{\beta}_{2}$ & -0.34 & -0.01 & 0.06 & 0.19 & 0.39 & 0.12 & 0.28 \\
\hline & $\mathrm{t}_{\hat{\beta}_{1}}$ & 44.41 & 28.12 & 38.22 & 15.93 & 31.41 & 27.15 & 29.86 \\
\hline & $\mathrm{t}_{\hat{\beta}_{2}}$ & -11.40 & -0.45 & 2.49 & 10.31 & 10.71 & 4.11 & 5.63 \\
\hline & $\mathrm{R}^{2}$ & 0.34 & 0.18 & 0.31 & 0.10 & 0.25 & 0.17 & 0.21 \\
\hline \multirow[t]{5}{*}{ Scale 1} & $\hat{\beta}_{1}$ & 1.52 & 0.38 & 0.76 & 0.30 & 0.99 & 0.63 & 0.76 \\
\hline & $\hat{\beta}_{2}$ & -0.21 & 0.00 & 0.08 & 0.20 & 0.42 & 0.04 & 0.14 \\
\hline & $\mathrm{t}_{\hat{\beta}_{1}}$ & 39.60 & 22.88 & 30.46 & 9.42 & 27.22 & 22.69 & 23.26 \\
\hline & $\mathrm{t}_{\hat{\beta}_{2}}$ & -6.49 & -0.18 & 3.77 & 10.79 & 10.53 & 1.47 & 2.82 \\
\hline & $\mathrm{R}^{2}$ & 0.29 & 0.12 & 0.23 & 0.06 & 0.20 & 0.12 & 0.13 \\
\hline \multirow[t]{5}{*}{ Scale 2} & $\hat{\beta}_{1}$ & 1.50 & 0.49 & 0.81 & 0.43 & 1.01 & 0.58 & 0.85 \\
\hline & $\hat{\beta}_{2}$ & -0.19 & 0.03 & 0.06 & 0.24 & 0.33 & 0.07 & 0.46 \\
\hline & $\mathrm{t}_{\hat{\beta}_{1}}$ & 46.12 & 30.33 & 36.44 & 13.97 & 35.15 & 23.48 & 28.21 \\
\hline & $\mathrm{t}_{\hat{\beta}_{2}}$ & -5.88 & 0.91 & 1.86 & 12.39 & 10.57 & 2.32 & 9.37 \\
\hline & $\mathrm{R}^{2}$ & 0.36 & 0.20 & 0.28 & 0.10 & 0.27 & 0.13 & 0.21 \\
\hline \multirow[t]{5}{*}{ Scale 3} & $\hat{\beta}_{1}$ & 1.40 & 0.46 & 0.86 & 0.60 & 0.91 & 0.75 & 0.97 \\
\hline & $\hat{\beta}_{2}$ & -0.20 & 0.16 & 0.05 & 0.15 & 0.54 & 0.31 & 0.42 \\
\hline & $\mathrm{t}_{\hat{\beta}_{1}}$ & 48.00 & 31.07 & 47.42 & 22.69 & 37.69 & 37.03 & 38.44 \\
\hline & $\mathrm{t}_{\hat{\beta}_{2}}$ & -5.46 & 4.05 & 1.96 & 9.21 & 16.31 & 12.62 & 8.49 \\
\hline & $\mathrm{R}^{2}$ & 0.38 & 0.22 & 0.43 & 0.16 & 0.37 & 0.33 & 0.33 \\
\hline \multirow[t]{5}{*}{ Scale 4} & $\hat{\beta}_{1}$ & 1.12 & 0.43 & 0.91 & 0.68 & 0.97 & 0.59 & 0.94 \\
\hline & $\hat{\beta}_{2}$ & 0.17 & -0.18 & -0.13 & 0.06 & 0.08 & 0.04 & 0.23 \\
\hline & $\mathrm{t}_{\hat{\beta}_{1}}$ & 34.69 & 25.09 & 52.04 & 24.08 & 38.75 & 27.42 & 34.90 \\
\hline & $\mathrm{t}_{\hat{\beta}_{2}}$ & 4.67 & -4.38 & -4.08 & 2.71 & 1.38 & 1.51 & 4.05 \\
\hline & $\mathrm{R}^{2}$ & 0.28 & 0.14 & 0.42 & 0.14 & 0.32 & 0.17 & 0.26 \\
\hline \multirow[t]{5}{*}{ Scale 5} & $\hat{\beta}_{1}$ & 1.78 & 0.51 & 0.86 & 0.35 & 0.46 & 0.69 & 1.18 \\
\hline & $\hat{\beta}_{2}$ & -0.37 & -0.18 & 0.08 & 0.28 & 0.75 & 0.40 & -0.13 \\
\hline & $\mathrm{t}_{\hat{\beta}_{1}}$ & 47.58 & 31.95 & 52.76 & 15.90 & 21.57 & 39.78 & 42.16 \\
\hline & $\mathrm{t}_{\hat{\beta}_{2}}$ & -7.33 & -4.65 & 4.21 & 16.81 & 17.14 & 20.10 & -2.20 \\
\hline & $\mathrm{R}^{2}$ & 0.37 & 0.21 & 0.45 & 0.15 & 0.18 & 0.37 & 0.34 \\
\hline \multirow[t]{5}{*}{ Scale 6} & $\hat{\beta}_{1}$ & 1.62 & 0.65 & 0.93 & 1.12 & 0.79 & 0.58 & 0.85 \\
\hline & $\hat{\beta}_{2}$ & -0.58 & -0.60 & -0.37 & 0.36 & 0.71 & -0.05 & 0.69 \\
\hline & $\mathrm{t}_{\hat{\beta}_{1}}$ & 57.77 & 38.98 & 57.17 & 39.80 & 39.25 & 28.86 & 34.28 \\
\hline & $\mathrm{t}_{\hat{\beta}_{2}}$ & -27.50 & -16.32 & -13.74 & 17.77 & 21.04 & -1.42 & 14.79 \\
\hline & $\mathrm{R}^{2}$ & 0.47 & 0.29 & 0.46 & 0.34 & 0.47 & 0.18 & 0.31 \\
\hline
\end{tabular}


(b) World market portfolio is the World MSCI Index

\begin{tabular}{|c|c|c|c|c|c|c|c|c|}
\hline & & Brazil & Chile & Mexico & Indonesia & Korea & Malaysia & Thailand \\
\hline \multirow[t]{5}{*}{ Raw data } & $\hat{\beta}_{1}$ & 0.92 & 0.37 & 0.86 & 0.20 & 0.48 & 0.31 & 0.43 \\
\hline & $\hat{\beta}_{2}$ & -0.18 & 0.08 & 0.25 & 0.23 & 0.55 & 0.21 & 0.53 \\
\hline & $\mathrm{t}_{\hat{\beta}_{1}}$ & 18.86 & 18.03 & 32.73 & 5.38 & 12.05 & 9.90 & 10.97 \\
\hline & $\mathrm{t}_{\hat{\beta}_{2}}$ & -5.00 & 2.29 & 9.87 & 12.41 & 13.88 & 6.78 & 9.72 \\
\hline & $\mathrm{R}^{2}$ & 0.09 & 0.08 & 0.25 & 0.05 & 0.09 & 0.04 & 0.06 \\
\hline \multirow[t]{5}{*}{ Scale 1} & $\hat{\beta}_{1}$ & 0.86 & 0.29 & 0.80 & -0.02 & 0.13 & 0.10 & 0.10 \\
\hline & $\hat{\beta}_{2}$ & 0.03 & 0.04 & 0.21 & 0.22 & 0.55 & 0.11 & 0.29 \\
\hline & $\mathrm{t}_{\hat{\beta}_{1}}$ & 17.67 & 15.23 & 29.41 & -0.60 & 2.90 & 3.00 & 2.51 \\
\hline & $\mathrm{t}_{\hat{\beta}_{2}}$ & 0.70 & 1.41 & 9.85 & 11.96 & 12.92 & 3.37 & 5.33 \\
\hline & $\mathrm{R}^{2}$ & 0.08 & 0.06 & 0.21 & 0.04 & 0.04 & 0.01 & 0.01 \\
\hline \multirow[t]{5}{*}{ Scale 2} & $\hat{\beta}_{1}$ & 0.96 & 0.43 & 0.86 & 0.22 & 0.59 & 0.32 & 0.48 \\
\hline & $\hat{\beta}_{2}$ & -0.05 & 0.11 & 0.26 & 0.27 & 0.41 & 0.14 & 0.67 \\
\hline & $\mathrm{t}_{\hat{\beta}_{1}}$ & 20.74 & 20.73 & 32.29 & 5.73 & 15.17 & 10.05 & 12.37 \\
\hline & $\mathrm{t}_{\hat{\beta}_{2}}$ & -1.34 & 3.01 & 8.04 & 13.86 & 11.60 & 4.33 & 13.03 \\
\hline & $\mathrm{R}^{2}$ & 0.10 & 0.11 & 0.24 & 0.06 & 0.09 & 0.03 & 0.08 \\
\hline \multirow[t]{5}{*}{ Scale 3} & $\hat{\beta}_{1}$ & 0.84 & 0.42 & 0.90 & 0.35 & 0.73 & 0.48 & 0.74 \\
\hline & $\hat{\beta}_{2}$ & 0.03 & 0.32 & 0.39 & 0.22 & 0.79 & 0.48 & 0.84 \\
\hline & $\mathrm{t}_{\hat{\beta}_{1}}$ & 18.92 & 21.59 & 40.20 & 10.16 & 22.48 & 16.88 & 21.39 \\
\hline & $\mathrm{t}_{\hat{\beta}_{2}}$ & 0.79 & 7.51 & 14.82 & 13.17 & 22.68 & 18.03 & 15.66 \\
\hline & $\mathrm{R}^{2}$ & 0.09 & 0.13 & 0.36 & 0.08 & 0.24 & 0.15 & 0.17 \\
\hline \multirow[t]{5}{*}{ Scale 4} & $\hat{\beta}_{1}$ & 0.67 & 0.37 & 0.93 & 0.54 & 0.93 & 0.67 & 0.67 \\
\hline & $\hat{\beta}_{2}$ & 0.49 & 0.04 & 0.12 & 0.16 & 0.62 & 0.10 & 0.60 \\
\hline & $\mathrm{t}_{\hat{\beta}_{1}}$ & 14.13 & 15.75 & 34.06 & 13.41 & 26.28 & 21.91 & 16.60 \\
\hline & $\mathrm{t}_{\hat{\beta}_{2}}$ & 12.68 & 0.99 & 3.14 & 6.47 & 10.71 & 3.84 & 9.60 \\
\hline & $\mathrm{R}^{2}$ & 0.11 & 0.06 & 0.24 & 0.06 & 0.20 & 0.12 & 0.09 \\
\hline \multirow[t]{5}{*}{ Scale 5} & $\hat{\beta}_{1}$ & 1.01 & 0.41 & 1.02 & 0.16 & 0.69 & 0.88 & 1.27 \\
\hline & $\hat{\beta}_{2}$ & -0.04 & -0.01 & 0.30 & 0.33 & 0.74 & 0.41 & 0.44 \\
\hline & $\mathrm{t}_{\hat{\beta}_{1}}$ & 15.65 & 17.20 & 42.70 & 5.19 & 23.08 & 34.81 & 31.81 \\
\hline & $\mathrm{t}_{\hat{\beta}_{2}}$ & -0.66 & -0.19 & 14.31 & 19.42 & 17.17 & 20.08 & 7.18 \\
\hline & $\mathrm{R}^{2}$ & 0.06 & 0.07 & 0.36 & 0.10 & 0.19 & 0.33 & 0.24 \\
\hline \multirow[t]{5}{*}{ Scale 6} & $\hat{\beta}_{1}$ & 1.46 & 0.52 & 0.89 & 0.93 & 1.10 & 0.35 & 0.54 \\
\hline & $\hat{\beta}_{2}$ & -0.46 & -0.48 & -0.15 & 0.35 & 0.69 & -0.07 & 0.77 \\
\hline & $\mathrm{t}_{\hat{\beta}_{1}}$ & 32.79 & 21.00 & 36.55 & 22.50 & 43.58 & 12.29 & 14.43 \\
\hline & $\mathrm{t}_{\hat{\beta}_{2}}$ & -17.99 & -11.30 & -4.84 & 15.61 & 21.24 & -1.71 & 14.43 \\
\hline & $\mathrm{R}^{2}$ & 0.23 & 0.11 & 0.26 & 0.18 & 0.50 & 0.04 & 0.14 \\
\hline
\end{tabular}

Note: The wavelet function is a symmmlet, s8. Scale 1: 2-4 days, scale 2: 4-8 days, scale 3: 8-16 day, scale 4: 16-32 days, scale 5: 32-64 days, and scale 6: 64-128 days. 
Table 3 MODWT-based estimates of international CAPM

\begin{tabular}{|c|c|c|c|c|c|c|c|c|}
\hline & & Brazil & Chile & Mexico & Indonesia & Korea & Malaysia & Thailand \\
\hline \multicolumn{9}{|c|}{ (a) World market portfolio is the Emerging Markets MSCI Index } \\
\hline \multirow[t]{3}{*}{ Scale 1} & $\hat{\beta}_{1}$ & 1.52 & 0.38 & 0.74 & 0.31 & 0.98 & 0.66 & 0.74 \\
\hline & $\hat{\beta}_{2}$ & -0.21 & -0.03 & 0.05 & 0.21 & 0.44 & 0.03 & 0.25 \\
\hline & $\mathrm{R}^{2}$ & 0.28 & 0.12 & 0.19 & 0.06 & 0.19 & 0.12 & 0.13 \\
\hline \multirow[t]{3}{*}{ Scale 2} & $\hat{\hat{\beta}_{1}}$ & 1.48 & 0.47 & 0.86 & 0.45 & 1.01 & 0.58 & 0.87 \\
\hline & $\hat{\beta}_{2}$ & -0.17 & 0.07 & 0.15 & 0.19 & 0.39 & 0.16 & 0.21 \\
\hline & $\mathrm{R}^{2}$ & 0.36 & 0.19 & 0.33 & 0.09 & 0.29 & 0.15 & 0.20 \\
\hline \multirow[t]{3}{*}{ Scale 3} & $\hat{\beta}_{1}$ & 1.37 & 0.46 & 0.84 & 0.59 & 0.97 & 0.71 & 0.98 \\
\hline & $\hat{\beta}_{2}$ & -0.02 & 0.12 & 0.03 & 0.22 & 0.36 & 0.22 & 0.62 \\
\hline & $\mathrm{R}^{2}$ & 0.37 & 0.22 & 0.41 & 0.17 & 0.36 & 0.28 & 0.33 \\
\hline \multirow[t]{3}{*}{ Scale 4} & $\hat{\beta}_{1}$ & 1.28 & 0.43 & 0.93 & 0.53 & 0.86 & 0.64 & 0.99 \\
\hline & $\hat{\beta}_{2}$ & -0.27 & -0.13 & -0.08 & 0.16 & 0.11 & 0.20 & 0.30 \\
\hline & $\mathrm{R}^{2}$ & 0.28 & 0.15 & 0.40 & 0.12 & 0.27 & 0.21 & 0.30 \\
\hline \multirow[t]{3}{*}{ Scale 5} & $\hat{\hat{\beta}_{1}}$ & 1.42 & 0.55 & 0.95 & 0.44 & 0.65 & 0.69 & 1.25 \\
\hline & $\hat{\beta}_{2}$ & -0.52 & -0.49 & 0.05 & 0.10 & 0.79 & 0.50 & -0.08 \\
\hline & $\mathrm{R}^{2}$ & 0.37 & 0.20 & 0.49 & 0.09 & 0.26 & 0.36 & 0.39 \\
\hline \multirow[t]{3}{*}{ Scale 6} & $\hat{\beta}_{1}$ & 1.68 & 0.93 & 0.84 & 1.14 & 0.84 & 0.42 & 0.85 \\
\hline & $\hat{\beta}_{2}$ & -0.82 & -0.40 & -0.02 & -0.07 & 0.30 & 0.00 & -0.16 \\
\hline & $\mathrm{R}^{2}$ & 0.45 & 0.48 & 0.41 & 0.29 & 0.37 & 0.12 & 0.23 \\
\hline \multicolumn{9}{|c|}{ (b) World market portfolio is the World MSCI Index } \\
\hline \multirow[t]{3}{*}{ Scale 1} & $\hat{\beta}_{1}$ & 0.85 & 0.30 & 0.80 & 0.00 & 0.14 & 0.09 & 0.06 \\
\hline & $\hat{\beta}_{2}$ & 0.02 & 0.02 & 0.18 & 0.23 & 0.57 & 0.10 & 0.40 \\
\hline & $\mathrm{R}^{2}$ & 0.07 & 0.06 & 0.20 & 0.04 & 0.04 & 0.00 & 0.02 \\
\hline \multirow[t]{3}{*}{ Scale 2} & $\hat{\beta}_{1}$ & 0.95 & 0.42 & 0.87 & 0.21 & 0.57 & 0.31 & 0.50 \\
\hline & $\hat{\beta}_{2}$ & -0.03 & 0.13 & 0.36 & 0.22 & 0.52 & 0.24 & 0.44 \\
\hline & $\mathrm{R}^{2}$ & 0.11 & 0.11 & 0.28 & 0.05 & 0.12 & 0.05 & 0.07 \\
\hline \multirow[t]{3}{*}{ Scale 3} & $\hat{\beta}_{1}$ & 0.88 & 0.40 & 0.88 & 0.34 & 0.75 & 0.51 & 0.74 \\
\hline & $\hat{\beta}_{2}$ & 0.19 & 0.29 & 0.30 & 0.29 & 0.55 & 0.39 & 1.02 \\
\hline & $\mathrm{R}^{2}$ & 0.10 & 0.12 & 0.32 & 0.09 & 0.18 & 0.12 & 0.17 \\
\hline \multirow[t]{3}{*}{ Scale 4} & $\hat{\beta}_{1}$ & 0.71 & 0.38 & 0.97 & 0.29 & 0.84 & 0.65 & 0.81 \\
\hline & $\hat{\beta}_{2}$ & 0.04 & 0.07 & 0.20 & 0.22 & 0.48 & 0.31 & 0.70 \\
\hline & $\mathrm{R}^{2}$ & 0.05 & 0.07 & 0.27 & 0.05 & 0.17 & 0.14 & 0.14 \\
\hline \multirow[t]{3}{*}{ Scale 5} & $\hat{\beta}_{1}$ & 0.99 & 0.40 & 0.96 & 0.39 & 0.87 & 0.70 & 1.20 \\
\hline & $\hat{\beta}_{2}$ & -0.28 & -0.30 & 0.27 & 0.12 & 0.73 & 0.52 & 0.28 \\
\hline & $\mathrm{R}^{2}$ & 0.10 & 0.07 & 0.31 & 0.05 & 0.26 & 0.26 & 0.23 \\
\hline \multirow[t]{3}{*}{ Scale 6} & $\hat{\beta}_{1}$ & 1.87 & 0.86 & 0.85 & 1.19 & 1.29 & 0.28 & 0.66 \\
\hline & $\hat{\beta}_{2}$ & -0.70 & -0.11 & 0.22 & 0.03 & 0.32 & -0.08 & 0.05 \\
\hline & $\mathrm{R}^{2}$ & 0.25 & 0.21 & 0.24 & 0.16 & 0.42 & 0.03 & 0.07 \\
\hline
\end{tabular}


Table 4 Aggregating time-scales: regression-based estimates

\begin{tabular}{|c|c|c|c|c|c|c|c|c|}
\hline & & Brazil & Chile & Mexico & Indonesia & Korea & Malaysia & Thailand \\
\hline \multicolumn{9}{|c|}{ (a) World market portfolio is the Emerging Markets MSCI Index } \\
\hline \multirow[t]{5}{*}{ Raw data } & $\hat{\beta}_{1}$ & 1.50 & 0.45 & 0.81 & 0.47 & 0.93 & 0.65 & 0.87 \\
\hline & $\hat{\beta}_{2}$ & -0.34 & -0.01 & 0.06 & 0.19 & 0.39 & 0.12 & 0.28 \\
\hline & $\mathrm{t}_{\hat{\beta}_{1}}$ & 44.41 & 28.12 & 38.22 & 15.93 & 31.41 & 27.15 & 29.86 \\
\hline & $\mathrm{t}_{\hat{\beta}_{2}}$ & -11.40 & -0.45 & 2.49 & 10.31 & 10.71 & 4.11 & 5.63 \\
\hline & $\mathrm{R}^{2}$ & 0.34 & 0.18 & 0.31 & 0.10 & 0.25 & 0.17 & 0.21 \\
\hline \multirow[t]{5}{*}{ Scales 1-2 } & $\hat{\beta}_{1}$ & 1.51 & 0.43 & 0.78 & 0.36 & 1.00 & 0.61 & 0.80 \\
\hline & $\hat{\beta}_{2}$ & -0.20 & 0.01 & 0.08 & 0.22 & 0.38 & 0.05 & 0.27 \\
\hline & $\mathrm{t}_{\hat{\beta}_{1}}$ & 42.02 & 25.98 & 32.83 & 11.30 & 29.98 & 22.97 & 25.30 \\
\hline & $\mathrm{t}_{\hat{\beta}_{2}}$ & -6.27 & 0.18 & 3.12 & 11.41 & 10.48 & 1.78 & 5.41 \\
\hline & $\mathrm{R}^{2}$ & 0.32 & 0.15 & 0.25 & 0.07 & 0.22 & 0.13 & 0.16 \\
\hline \multirow[t]{5}{*}{ Scales 1-4 } & $\hat{\beta}_{1}$ & 1.45 & 0.43 & 0.81 & 0.44 & 0.98 & 0.64 & 0.85 \\
\hline & $\hat{\beta}_{2}$ & -0.18 & 0.01 & 0.06 & 0.20 & 0.40 & 0.11 & 0.30 \\
\hline & $\mathrm{t}_{\hat{\beta}_{1}}$ & 42.54 & 26.91 & 36.77 & 14.46 & 31.85 & 25.86 & 28.54 \\
\hline & $\mathrm{t}_{\hat{\beta}_{2}}$ & -5.39 & 0.35 & 2.54 & 10.50 & 10.90 & 3.71 & 5.87 \\
\hline & $\mathrm{R}^{2}$ & 0.32 & 0.16 & 0.29 & 0.09 & 0.25 & 0.16 & 0.20 \\
\hline \multicolumn{9}{|c|}{ (b) World market portfolio is the World MSCI Index } \\
\hline \multirow[t]{5}{*}{ Raw data } & $\hat{\beta}_{1}$ & 0.92 & 0.37 & 0.86 & 0.20 & 0.48 & 0.31 & 0.43 \\
\hline & $\hat{\beta}_{2}$ & -0.18 & 0.08 & 0.25 & 0.23 & 0.55 & 0.21 & 0.53 \\
\hline & $\mathrm{t}_{\hat{\beta}_{1}}$ & 18.86 & 18.03 & 32.73 & 5.38 & 12.05 & 9.90 & 10.97 \\
\hline & $\mathrm{t}_{\hat{\beta}_{2}}$ & -5.00 & 2.29 & 9.87 & 12.41 & 13.88 & 6.78 & 9.72 \\
\hline & $\mathrm{R}^{2}$ & 0.09 & 0.08 & 0.25 & 0.05 & 0.09 & 0.04 & 0.06 \\
\hline \multirow[t]{5}{*}{ Scales 1-2 } & $\hat{\beta}_{1}$ & 0.90 & 0.35 & 0.83 & 0.07 & 0.31 & 0.18 & 0.25 \\
\hline & $\hat{\beta}_{2}$ & 0.00 & 0.06 & 0.22 & 0.24 & 0.50 & 0.12 & 0.44 \\
\hline & $\mathrm{t}_{\hat{\beta}_{1}}$ & 18.83 & 17.47 & 30.55 & 1.94 & 7.20 & 5.64 & 6.32 \\
\hline & $\mathrm{t}_{\hat{\beta}_{2}}$ & -0.05 & 1.98 & 9.15 & 12.75 & 12.45 & 3.73 & 8.36 \\
\hline & $\mathrm{R}^{2}$ & 0.09 & 0.08 & 0.22 & 0.04 & 0.05 & 0.01 & 0.03 \\
\hline \multirow[t]{5}{*}{ Scales 1-4 } & $\hat{\beta}_{1}$ & 0.88 & 0.36 & 0.85 & 0.16 & 0.44 & 0.28 & 0.38 \\
\hline & $\hat{\beta}_{2}$ & 0.04 & 0.09 & 0.24 & 0.24 & 0.56 & 0.20 & 0.52 \\
\hline & $\mathrm{t}_{\hat{\beta}_{1}}$ & 18.61 & 18.06 & 32.48 & 4.35 & 11.00 & 8.74 & 9.81 \\
\hline & $\mathrm{t}_{\hat{\beta}_{2}}$ & 0.97 & 2.64 & 9.56 & 12.44 & 14.11 & 6.39 & 9.63 \\
\hline & $\mathrm{R}^{2}$ & 0.08 & 0.08 & 0.25 & 0.05 & 0.08 & 0.03 & 0.05 \\
\hline
\end{tabular}


Table 5 Aggregating time-scales: MODWT-based estimates

\begin{tabular}{lllllcccc}
\hline & & Brazil & Chile & Mexico & Indonesia & Korea & Malaysia & Thailand \\
\hline Scales 1-2 & $\hat{\beta}_{1}$ & (a) World market portfolio is the Emerging Markets MSCI Index & & \\
& $\hat{\beta}_{2}$ & -0.51 & 0.42 & 0.79 & 0.37 & 0.99 & 0.62 & 0.80 \\
& $\mathrm{R}^{2}$ & 0.31 & 0.00 & 0.08 & 0.20 & 0.41 & 0.07 & 0.24 \\
& $\hat{\beta}_{1}$ & 1.45 & 0.43 & 0.81 & 0.43 & 0.97 & 0.65 & 0.86 \\
& $\hat{\beta}_{2}$ & -0.18 & 0.01 & 0.06 & 0.20 & 0.39 & 0.11 & 0.30 \\
& $\mathrm{R}^{2}$ & 0.31 & 0.16 & 0.27 & 0.09 & 0.24 & 0.16 & 0.19 \\
\hline Scales 1-4 & & (b) World market portfolio is the World MSCI Index & & \\
\hline & $\hat{\beta}_{1}$ & 0.89 & 0.35 & 0.83 & 0.09 & 0.32 & 0.18 & 0.25 \\
& $\hat{\beta}_{2}$ & 0.01 & 0.06 & 0.23 & 0.23 & 0.55 & 0.15 & 0.42 \\
& $\mathrm{R}^{2}$ & 0.08 & 0.08 & 0.23 & 0.04 & 0.06 & 0.02 & 0.03 \\
& $\hat{\beta}_{1}$ & 0.87 & 0.36 & 0.85 & 0.15 & 0.44 & 0.28 & 0.38 \\
& $\hat{\beta}_{2}$ & 0.03 & 0.08 & 0.24 & 0.24 & 0.56 & 0.20 & 0.53 \\
& $\mathrm{R}^{2}$ & 0.08 & 0.08 & 0.24 & 0.05 & 0.08 & 0.03 & 0.05 \\
\hline
\end{tabular}

Table 6 95-percent VaR computations for a USD 100-investment

\begin{tabular}{lcccc}
\hline & \multicolumn{2}{c}{ MODWT-based estimates } & \multicolumn{2}{c}{ Regression-based estimates } \\
& EM portfolio & World portfolio & EM portfolio & World portfolio \\
\hline Raw data & 2.249 & 1.853 & 2.249 & 1.853 \\
Scale 1 & 1.332 & 1.095 & 1.341 & 1.101 \\
Scale 2 & 1.178 & 1.000 & 1.134 & 0.964 \\
Scale 3 & 1.024 & 0.857 & 1.057 & 0.896 \\
Scale 4 & 0.623 & 0.527 & 0.611 & 0.509 \\
Scale 5 & 0.434 & 0.377 & 0.462 & 0.395 \\
Scale 6 & 0.386 & 0.341 & 0.389 & 0.343 \\
Scales 1-4 & 2.129 & 1.759 & 2.121 & 1.750 \\
Scales 1-2 & 1.760 & 1.453 & 1.679 & 1.421 \\
\hline
\end{tabular}

Table 7 MODWT-based estimates of 95-percent marginal VaR (in US dollars)

\begin{tabular}{|c|c|c|c|c|c|c|c|}
\hline & Brazil & Chile & Mexico & Indonesia & Korea & Malaysia & Thailand \\
\hline \multicolumn{8}{|c|}{ (a) World market portfolio is the Emerging Markets MSCI Index } \\
\hline Raw data & 0.024 & 0.007 & 0.025 & 0.031 & 0.019 & 0.014 & 0.015 \\
\hline Scale 1 & 0.016 & 0.004 & 0.017 & 0.021 & 0.013 & 0.010 & 0.009 \\
\hline Scale 2 & 0.011 & 0.004 & 0.035 & 0.016 & 0.011 & 0.007 & 0.008 \\
\hline Scale 3 & 0.009 & 0.003 & 0.030 & 0.014 & 0.008 & 0.006 & 0.007 \\
\hline Scale 4 & 0.006 & 0.002 & 0.007 & 0.007 & 0.004 & 0.004 & 0.004 \\
\hline Scale 5 & 0.004 & 0.001 & 0.008 & 0.005 & 0.003 & 0.003 & 0.003 \\
\hline Scale 6 & 0.003 & 0.001 & 0.008 & 0.004 & 0.002 & 0.001 & 0.002 \\
\hline \multicolumn{8}{|c|}{ (b) World market portfolio is the World MSCI Index } \\
\hline Raw data & 0.026 & 0.006 & 0.031 & 0.038 & 0.020 & 0.015 & 0.015 \\
\hline Scale 1 & 0.017 & 0.004 & 0.020 & 0.025 & 0.014 & 0.009 & 0.009 \\
\hline Scale 2 & 0.012 & 0.003 & 0.036 & 0.019 & 0.010 & 0.007 & 0.008 \\
\hline Scale 3 & 0.009 & 0.002 & 0.033 & 0.017 & 0.008 & 0.007 & 0.006 \\
\hline Scale 4 & 0.008 & 0.002 & 0.008 & 0.008 & 0.004 & 0.004 & 0.004 \\
\hline Scale 5 & 0.006 & 0.001 & 0.009 & 0.007 & 0.002 & 0.004 & 0.003 \\
\hline Scale 6 & 0.004 & 0.001 & 0.008 & 0.005 & 0.002 & 0.001 & 0.002 \\
\hline
\end{tabular}


Figure 1 Multi-resolution decomposition (MRD) of Thai data

Thai baht/US dollar-exchange rate variation

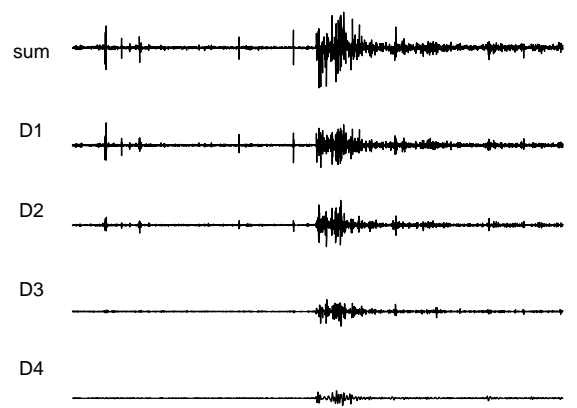

D5

D6

D7

S7

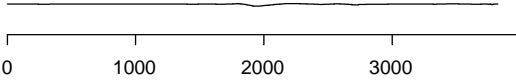

Return on Thai stock index in local currency

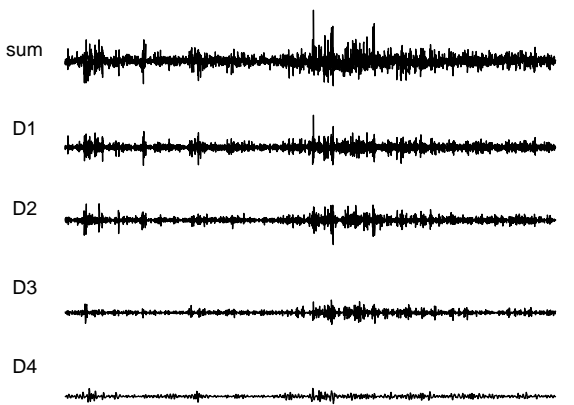

D5

D6

D7

S7

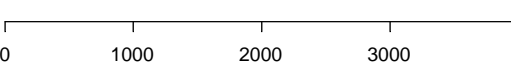

Figure 2 Regression-based estimates of market and exchange rate risk for Thailand

Raw data

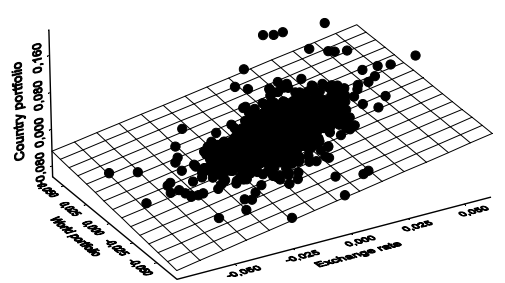

Scale 3

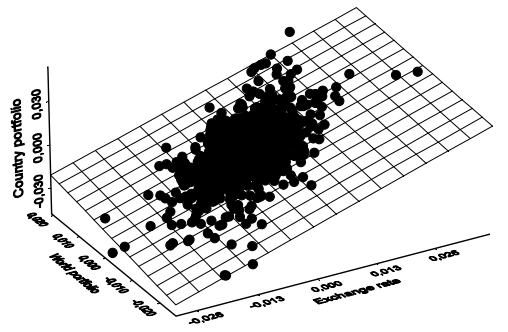

Scale 1

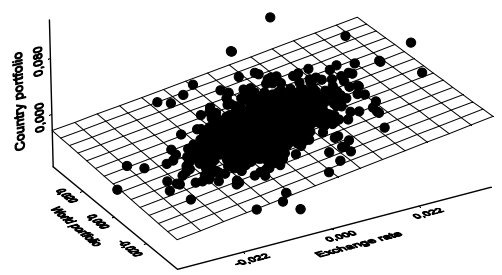

Scale 5

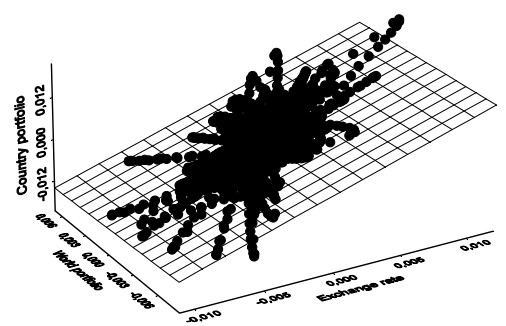

Notes to Figures 1 and 2: The time period is 1990-2004. Returns are logarithmic and measured at a daily frequency. The data source is Morgan Stanley. The wavelet function is a symmmlet, s8. Scale 1: 2-4 days, scale 2: 4-8 days, scale 3: 8-16 days, scale 4: 16-32 days, scale 5: 32-64 days, and scale 6: 64-128 days. In Figure 2, the world market portfolio is the Emerging Markets MSCI Index. 